\title{
Alcohol Intake and Risk of Lethal Prostate Cancer in the Health Professionals Follow-Up Study
}

Mary K. Downer, PhD, SM ${ }^{1,2}$; Stacey A. Kenfield, ScD ${ }^{2,3}$; Meir J. Stampfer, MD, DrPH ${ }^{1,2}$; Kathryn M. Wilson, ScD ${ }^{1,2}$;

Barbra A. Dickerman, MSc ${ }^{1}$; Edward L. Giovannucci, MD, ScD ${ }^{1,2}$; Eric B. Rimm, ScD ${ }^{1,2}$; Molin Wang, PhD ${ }^{1}$; Lorelei A. Mucci, ScD ${ }^{1,2}$; Walter C. Willett, MD, DrPH ${ }^{1,2}$; June M. Chan, ScD ${ }^{3}$; and Erin L. Van Blarigan, ScD ${ }^{3}$

PURPOSE It is unknown whether alcohol intake is associated with the risk of lethal (metastatic or fatal) prostate cancer. We examine (1) whether alcohol intake among men at risk of prostate cancer is associated with diagnosis of lethal prostate cancer and (2) whether intake among men with nonmetastatic prostate cancer is associated with metastasis or death.

METHODS This prospective cohort study uses the Health Professionals Follow-Up Study (1986 to 2012). Our analysis of alcohol intake among men at risk of prostate cancer included 47,568 cancer-free men. Our analysis of alcohol intake among men with prostate cancer was restricted to 5,182 men diagnosed with nonmetastatic prostate cancer during follow-up. We examine the association of total alcohol, red and white wine, beer, and liquor with lethal prostate cancer and death. Multivariate Cox proportional hazards regression estimated hazard ratios (HRs) and 95\% Cls.

RESULTS Alcohol drinkers had a lower risk of lethal prostate cancer (any $v$ none: $\mathrm{HR}, 0.84$ [95\% Cl, 0.71 to 0.99]) without a dose-response relationship. Total alcohol intake among patients with prostate cancer was not associated with progression to lethal prostate cancer (any $v$ none: $\mathrm{HR}, 0.99$ [95\% Cl, 0.57 to 1.72]), whereas moderate red wine intake was associated with a lower risk (any $v$ none: $\mathrm{HR}, 0.50$ [95\% $\mathrm{Cl}, 0.29$ to 0.86 ]; $P$ trend $=.05)$. Compared with none, 15 to $30 \mathrm{~g} / \mathrm{d}$ of total alcohol after prostate cancer diagnosis was associated with a lower risk of death (HR, 0.71 [95\% $\mathrm{Cl}, 0.50$ to 1.00$]$ ), as was red wine (any $v$ none: $\mathrm{HR}, 0.74$ [95\% $\mathrm{Cl}, 0.57$ to 0.97]; $P$ trend $=.007$ ).

CONCLUSION Cancer-free men who consumed alcohol had a slightly lower risk of lethal prostate cancer compared with abstainers. Among men with prostate cancer, red wine was associated with a lower risk of progression to lethal disease. These observed associations merit additional study but provide assurance that moderate alcohol consumption is safe for patients with prostate cancer.

J Clin Oncol 37:1499-1511. @ 2019 by American Society of Clinical Oncology

\section{INTRODUCTION}

More than three million men in the United States are living with diagnosed prostate cancer., ${ }^{1,2}$ Epidemiologic studies consistently demonstrate a lower risk of death among moderate alcohol drinkers compared with abstainers, likely because of cardiovascular benefits. ${ }^{3,4}$ However, alcohol intake is associated with an increased risk of several cancers. ${ }^{5}$ It remains unknown whether moderate alcohol intake (total and by type) is associated with prostate cancer, and no study has examined intake after diagnosis.

Studies of alcohol and prostate cancer report mixed results. ${ }^{6-18}$ Prospective studies ${ }^{6,7,17,18}$ have observed inverse associations between alcohol and the risk of advanced or fatal prostate cancer, but these studies have been limited by small numbers of events. We reported previously that, on the basis of follow-up through 1998, daily alcohol drinkers had a $24 \%$ lower risk of lethal prostate cancer (distant metastases or prostate cancer death) compared with abstainers, without statistical significance. ${ }^{7}$

In this article, we updated these findings with 14 more years of follow-up and 611 lethal prostate cancer events. We prospectively examined alcohol intake in relation to the risk of lethal prostate cancer. First, we investigated alcohol intake and the risk of developing lethal prostate cancer among men at risk of prostate cancer. Second, among the subset of participants diagnosed with nonmetastatic prostate cancer during follow-up, we investigated postdiagnostic alcohol intake and the risk of progression to lethal prostate cancer and death.

\section{METHODS}

\section{Study Population}

The Health Professionals Follow-Up Study is a prospective cohort study of 51,529 male health 
professionals 40 to 75 years of age in the United States. Biennial questionnaires beginning in 1986 ask men to report on their medical history, lifestyle, diet (including alcohol every 4 years), and medications. Average follow-up rates exceed $90 \%$.

The analysis of alcohol intake among men at risk of prostate cancer excluded participants who did not complete the baseline food frequency questionnaire (FFQ), those with cancer before baseline (with the exception of nonmelanoma skin cancer), and those who reported cliniciandiagnosed alcohol dependency at baseline $(n=325)$, leaving 47,568 participants for analysis.

The analysis of alcohol intake among men with nonmetastatic prostate cancer was further restricted to participants diagnosed between 1986 and $2012(n=5,182)$.

\section{Exposure}

Participants completed validated semiquantitative FFQs every 4 years, described in detail elsewhere. ${ }^{19}$ Alcoholic beverages included red and white wine separately (4 ounces, increasing to 5 ounces in 2006), beer (one glass, can, or bottle), and liquor (one drink or shot). We multiplied the amount of alcohol in grams per specified portion size by servings/day, determined the midpoint of the frequency category, and summed across all beverages to estimate total alcohol intake (grams/day [g/d]). The amount of alcohol for the specified portion size was based on United States Department of Agriculture nutrient composition tables. In a subset of questionnaires, the men were also asked to report the number of days per week that they consumed alcohol. In a validation study, the de-attenuated correlation coefficients between diet records and FFQs were 0.83 for red wine, 0.78 for white wine, 0.88 for beer, and 0.85 for liquor. ${ }^{19,20}$ The correlation between alcohol measured by the FFQ and high-density lipoprotein cholesterol, a biomarker sensitive, but not specific, to alcohol intake, was $0.40 .^{21}$

\section{Outcomes}

Our primary end point for all analyses, chosen a priori on the basis of clinical significance, was lethal prostate cancer (cancer that metastasized to bone or distant organs or that was identified as a cause of death). Overall mortality was an additional end point in our analysis of alcohol intake among men with nonmetastatic prostate cancer, because most patients with prostate cancer die as a result of other causes.

The men reported incident prostate cancer diagnoses on biennial questionnaires; this information was confirmed by manual medical record review. We extracted TNM stage ( $85 \%$ complete), biopsy Gleason grade ( $80 \%$ complete), and initial treatment ( $82 \%$ complete) from medical records. Starting in 2000, participants reported metastases, and other clinical information, on prostate cancer follow-up questionnaires. Deaths were identified through the postal system, by next of kin, and by the National Death Index.
Study physicians reviewed medical records and death certificate information to determine the cause of death, including those deaths resulting from prostate cancer. Follow-up for overall and prostate cancer mortality was virtually complete through 2012. ${ }^{22}$

\section{Statistical Analysis}

We used multivariate Cox proportional hazards regression to estimate hazard ratios (HR) and 95\% Cls. Age (months) was the time scale and we stratified by age and calendar year.

\section{Analysis of alcohol intake among men at risk of prostate}

cancer. Person-time accrued from 1986 baseline until prostate cancer diagnosis, death, or end of follow-up (January 2012). For men who developed lethal prostate cancer over follow-up, their event date was their date of prostate cancer diagnosis. To focus on associations between alcohol intake among cancer-free men and lethal prostate cancer, those men diagnosed with nonmetastatic prostate cancer were censored at diagnosis.

We first categorized intake for all alcohol exposures into any or none. On the basis of the distribution of intake, and to distinguish men drinking more than the recommended limit of two servings per day (approximately $30 \mathrm{~g} / \mathrm{d}$ ), we further categorized total alcohol intake as zero, more than zero to fewer than 10, 10 to fewer than 15, 15 to fewer than 30, and 30 or more grams/day. We categorized the wine, beer, and liquor as zero, more than zero to fewer than one, more than one to fewer than three, more than three to fewer than seven, and seven or more servings per week. To evaluate a dose-response relationships, we created a semicontinuous variable using the median of each category of intake, and used the Wald test $P$ value to assess the significance of the trend. We categorized drinking frequency as 0,1 to 2,3 to 4,5 to 6 , or 7 days per week. Cumulative average alcohol intake (across all reports from baseline until most recent questionnaire) was updated every 4 years. For missing values, we carried forward the previous value one cycle; if a second consecutive value was missing, individuals did not contribute person-time for the subsequent 4-year time periods.

We adjusted multivariate models for factors associated with lethal prostate cancer and alcohol intake, on the basis of prior literature. This included total energy intake (kilocalories/day, continuous), smoking (never, quit more than 10 years ago, quit 10 years ago or less, current and fewer than 40 pack-years, current and 40 pack-years or more), body mass index $\left(\mathrm{kg} / \mathrm{m}^{2}\right.$; less than 25,25 to less than 30 , 30 or higher), vigorous physical activity (hours per week; less than 3, 3 or more), choline (milligrams/day, quintiles), vegetable fat (grams/day, quintiles), coffee (servings/day, quintiles), lycopene (servings/day, quintiles), whole milk (servings/day, quintiles), and diabetes (yes or no). We also adjusted for prostate-specific antigen (PSA) screening beginning in 1994 (report of screening on the previous 
cycle [yes or no] and report of PSA screening on 50\% or more of previous cycles [yes or no]). Beer, wine, and liquor were mutually adjusted for each other, as were red and white wine. To avoid misclassifying diagnostic PSA tests as screening tests, we did not include screening reports from the questionnaire on which a prostate cancer diagnosis was reported. All covariates were updated over follow-up. We also ran models adjusting for other possible confounders, but including those covariates did not meaningfully change the associations.

We conducted several sensitivity analyses. First, because PSA screening may confound the association (ie, healthconscious men may screen more frequently and drink alcohol moderately; screening reduces risk of lethal prostate cancer), we restricted our analyses to men who reported PSA screening on both 1994 and 1996 questionnaires (starting follow-up in 1996; PSA screening was first assessed in 1994). Second, we restricted our analyses to never-smokers because of potential confounding by smoking. Third, because men may significantly decrease alcohol intake for unidentifiable reasons that may be associated with prostate cancer risk (eg, health consciousness, comorbidities, and so forth), we excluded those men who reported at baseline that they had decreased their alcohol intake in the past 10 years. Fourth, we assessed alcohol intake on the basis of the most recent exposure only, to analyze the impact of current intake (rather than cumulative average). Fifth, to further explore recent alcohol intake, we continued updating cumulative alcohol exposure after prostate cancer diagnosis instead of censoring at diagnosis, with outcome defined as date of lethal prostate cancer diagnosis (metastasis or prostate cancer death, whichever came first). Sixth, to examine reverse causation (whereby men with a greater likelihood of lethal prostate cancer decrease their intake as a result of their disease), we applied alcohol exposures from 2 to 4,4 to 6 , and 6 to 8 years before the current exposure period to the current period (lagged analyses). Last, we made no alcohol (rather than zero servings/d of the specific beverage) the referent group for beer, wine, and liquor.

We also analyzed alcohol in relation to overall mortality as a secondary outcome. Here, alcohol intake was updated until death or end of follow-up. However, if a participant was diagnosed with prostate cancer, we censored him at diagnosis.

To evaluate interaction between the amount and frequency of alcohol intake, we stratified total alcohol analyses on drinking frequency (2 or fewer $v$ more than 2 days per week) among drinkers, testing for interaction with a likelihood ratio test.

Analysis of alcohol intake among men with nonmetastatic prostate cancer. Cox models were stratified on years since diagnosis, age, and calendar year. Person-time was accrued from first postdiagnostic alcohol report until outcome. Exposures were identical to our analysis of alcohol intake among men at risk of prostate cancer, but we used only reports after diagnosis.

Using the same approach as discussed earlier, our multivariate models were adjusted for energy intake, smoking, body mass index, vigorous physical activity, diabetes, coffee intake, and other alcohol subtypes (where applicable) measured at the time of diagnosis. We also adjusted for clinical variables: primary treatment (radical prostatectomy, radiation, hormones, other, missing), TNM stage at diagnosis (T1, T2, T3+, missing), Gleason grade (less than 7, 7, higher than 7, missing), PSA at diagnosis (less than $4 \mathrm{ng} / \mathrm{dL}$, 4 to less than $10 \mathrm{ng} / \mathrm{dL}, 10$ to less than $20 \mathrm{ng} / \mathrm{dL}, 20 \mathrm{ng} / \mathrm{dL}$ or greater, missing), and PSA screening (screening on cycle before diagnosis [yes or no]; intensity of prediagnosis screening [50\% or more of previous cycles (yes or no)]). Models for overall mortality also adjusted for parental history of myocardial infarction before age 60 years (yes or no), comorbidities updated over follow-up (yes or no [yes if myocardial infarction, angina, coronary artery bypass or angioplasty, stroke, emphysema or chronic obstructive pulmonary disease, or Parkinson's disease]), high blood pressure (yes or no), and high cholesterol (yes or no).

We conducted several sensitivity analyses. To evaluate residual confounding from missing TNM stage $(n=451)$, we excluded men missing that stage. To further examine confounding by PSA screening, we separately restricted our analyses to men who reported one or more and two or more PSA screens before diagnosis. To further address potential confounding by smoking, we restricted our analyses to never-smokers. To examine the possibility of reverse causation, we defined alcohol exposure on the basis of the first postdiagnostic report only (no updating). We also applied alcohol exposure from 2 to 4 years before the current period (lagged analysis) Last, we examined whether change in alcohol intake from the last prediagnostic questionnaire to the first postdiagnostic questionnaire was associated with our outcomes. All statistical analyses were performed using SAS (Version 9.3, SAS Institute, Cary, NC) and two-sided $P$ values $<.05$ were considered statistically significant.

\section{RESULTS \\ Analysis of Alcohol Intake Among Men at Risk of Prostate Cancer}

We observed 869 lethal prostate cancer events among 47,568 participants observed for a median of 25.3 years (interquartile range, 24.8-25.8 years). At the 1986 baseline, men who drank more alcohol were more likely to be white, smokers, active, and nondiabetic, and to consume more calories, less vegetable fat, and more coffee (Table 1). Individual alcohol beverages were associated with similar variables.

Among cancer-free men, alcohol intake was associated with a lower risk of lethal prostate cancer (any $v$ none: HR, 0.84 [95\% $\mathrm{Cl}, 0.71$ to 0.99$]$ ), with no dose-response relationship 
( $P$ trend $=.37$ ). There were no statistically significant associations with lethal prostate cancer (Table 2).

In sensitivity analyses, associations were virtually unchanged when restricting to nonsmokers ( $n=44,179$ ), updating alcohol exposure after initial diagnosis $(n=$ 47,568), censoring at date of lethal prostate cancer (rather than at diagnosis), or updating intake every 4 years (rather than cumulative average; $n=47,568$ ). After restricting our analyses to men screened in 1994 and $1996(n=13,426)$, the association became stronger (HR, $0.74[95 \% \mathrm{Cl}, 0.47$ to 1.15]). After excluding men who reported decreased intake at baseline ( $n=29,057)$, the association was attenuated (HR, 1.04 [95\% Cl, 0.79 to 1.38]; Appendix Table $A 1$, online only). Lagged analyses did not meaningfully change the results (Appendix Table A2, online only).

Changing the referent group for individual alcohol beverages to nondrinkers (rather than zero servings/d of the specific beverage) did not meaningfully change the results. There was no association between drinking frequency and risk of lethal prostate cancer, and no interaction between drinking frequency and total alcohol intake (results not shown). Total alcohol, wine (total, red, and white) and beer were associated with lower overall mortality (Appendix Table A3, online only).

\section{Analysis of Alcohol Intake Among Men With Nonmetastatic Prostate Cancer}

At diagnosis, men who drank more alcohol were more likely to be white, smokers, and nondiabetic. They consumed less vegetable fat and more coffee, engaged in more vigorous activity, and were more likely to be diagnosed with $\mathrm{T} 1$ disease and a Gleason score of less than 7 (Table 3). Specific alcoholic beverages were associated with similar variables overall.

Among the 5,182 men diagnosed with nonmetastatic prostate cancer, alcohol intake after diagnosis was not associated with progression to lethal prostate cancer (any $\mathrm{v}$ none: $\mathrm{HR}, 0.99$ [95\% Cl, 0.57 to 1.72]). However, red wine intake after diagnosis was inversely associated (HR, 0.50 [95\% Cl, 0.29 to 0.86]; $P$ trend across five categories of intake $=.05)$. Total alcohol intake was borderline inversely associated with lower overall mortality (any $v$ none: HR, 0.82 [95\% Cl, 0.64 to 1.04]; $P$ trend $=.20$ ), with the lowest risk in the 15 to $30 \mathrm{~g} / \mathrm{d}$ category (HR, $0.71[95 \% \mathrm{Cl}, 0.50$ to 1.00]). Red wine intake after prostate cancer diagnosis was also associated with lower overall mortality (any $v$ none: HR, 0.74 [95\% Cl, 0.57 to 0.97]; $P$ trend $=.007$ ). Other alcohol beverages were not associated with either outcome (Table 4).

Overall, associations did not change meaningfully in sensitivity analyses, although we observed wide Cls because of diminished statistical power for many analyses. Associations between red wine and lethal prostate cancer and overall mortality were attenuated when only the first postdiagnostic report of alcohol was used (Appendix Tables A4 and $A 5$, online only). Point estimates were largely unchanged when lagging exposures 2 to 4 years, although the Cls were wide (Appendix Table A6, online only). Change in

TABLE 1. Age-Standardized Baseline Characteristics of Cancer-Free Men in the Health Professionals Follow-Up Study, by Alcohol Intake (Analysis of Alcohol Intake Among Men at Risk for Prostate Cancer, 1986 to 2012; N = 47,568)

Alcohol Intake at Baseline $(\mathrm{g} / \mathrm{d})$

\begin{tabular}{|c|c|c|c|c|c|}
\hline \multirow[b]{2}{*}{ Characteristic } & \\
\hline & None & $>0$ to $<10$ & 10 to $<15$ & 15 to $<30$ & $\geq 30$ \\
\hline$n$ & 11,128 & 18,504 & 6,056 & 6,263 & 6,518 \\
\hline Age, years & 54 & 54 & 55 & 55 & 55 \\
\hline White, \% & 89 & 91 & 92 & 92 & 93 \\
\hline $\mathrm{BMI}, \mathrm{kg} / \mathrm{m}^{2}$ & 25.7 & 25.5 & 25.4 & 25.3 & 25.6 \\
\hline Vigorous physical activity, MET-h/wk & 8.9 & 10.7 & 11.3 & 11.6 & 9.4 \\
\hline Family history of prostate cancer, \% & 12 & 12 & 12 & 12 & 12 \\
\hline Current smoker, \% & 7 & 8 & 10 & 10 & 22 \\
\hline Diabetes, \% & 5 & 3 & 2 & 2 & 2 \\
\hline PSA screening reported on 1994 questionnaire, \% & 31 & 37 & 36 & 36 & 33 \\
\hline Energy, kcal/d & 1,921 & 1,933 & 1,956 & 2,073 & 2,214 \\
\hline Vegetable fat, g/d & 31.4 & 30.5 & 30.2 & 29.9 & 26.4 \\
\hline Coffee, servings/d & 1.4 & 1.8 & 2.1 & 2.3 & 2.6 \\
\hline Whole milk, servings/d & 0.2 & 0.2 & 0.2 & 0.1 & 0.2 \\
\hline Choline, mg/d & 398 & 400 & 404 & 400 & 399 \\
\hline Lycopene, $\mu \mathrm{g} / \mathrm{d}$ & 723 & 759 & 736 & 749 & 677 \\
\hline
\end{tabular}

NOTE. Data are presented as means unless indicated otherwise.

Abbreviations: BMI, body mass index; PSA, prostate-specific antigen. 


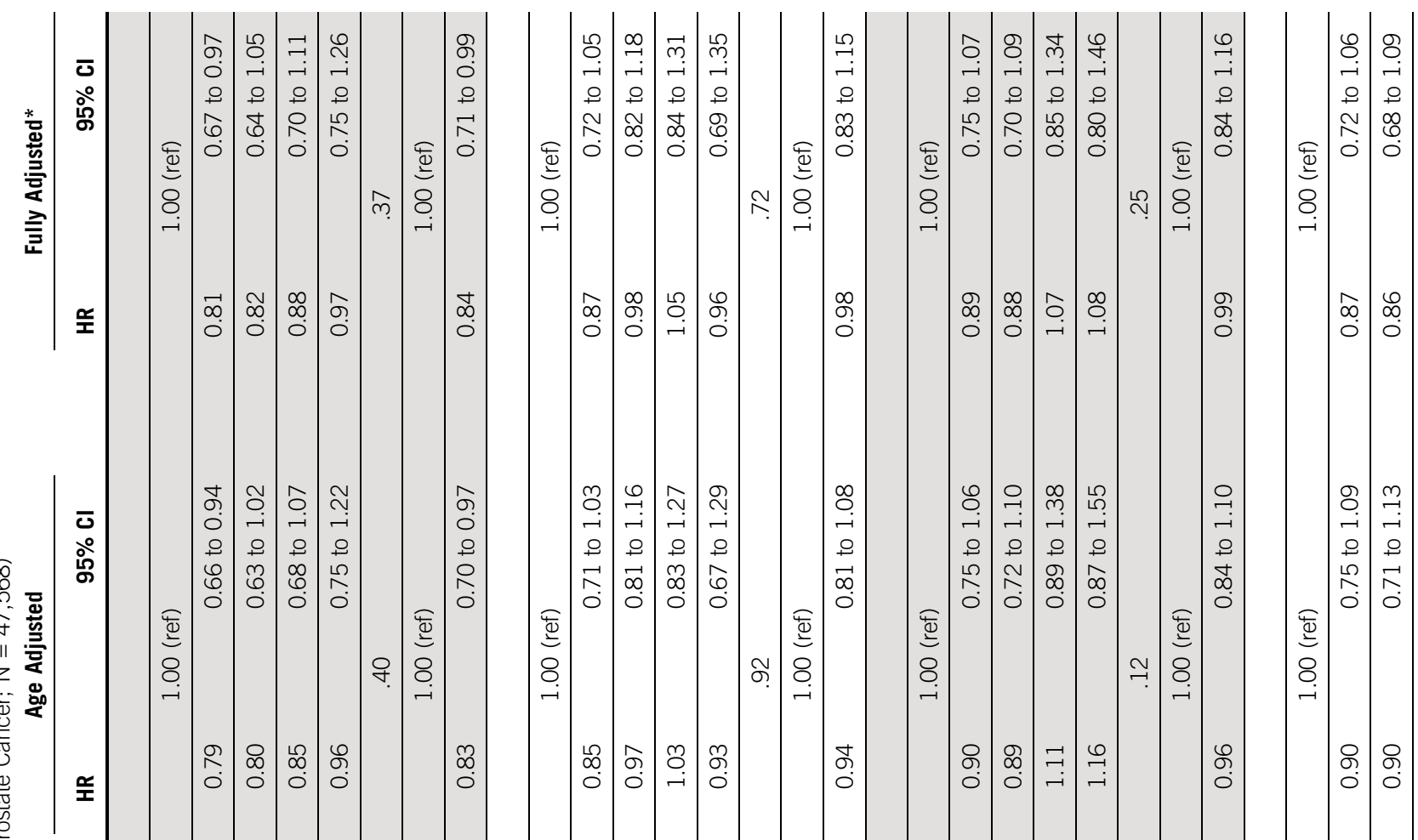




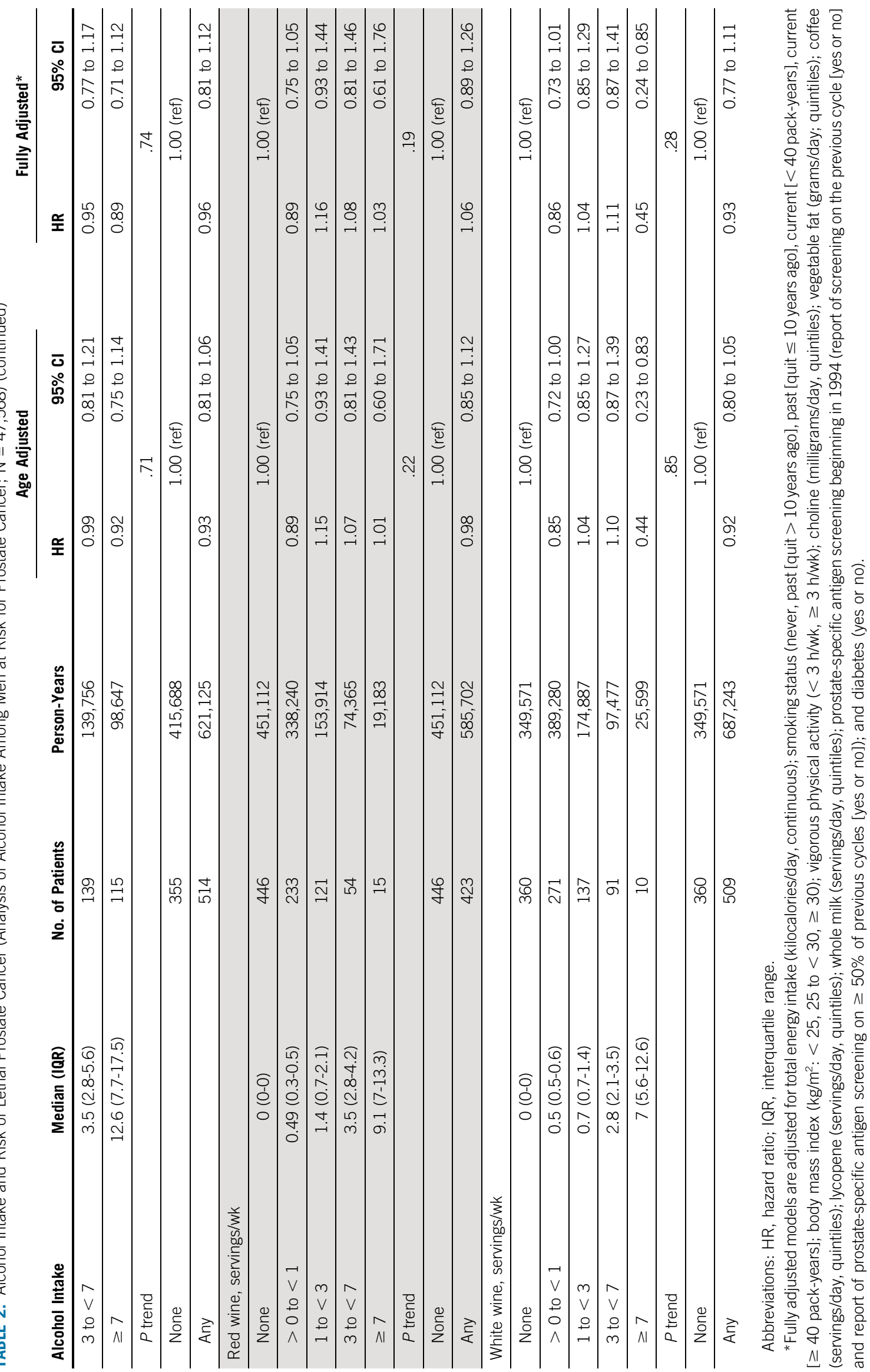


TABLE 3. Age-Standardized Characteristics of Men in the Health Professionals Follow-Up Study Diagnosed With Nonmetastatic Prostate Cancer During Follow-Up, by Alcohol Intake at Diagnosis (Analysis of Alcohol Intake Among Men With Nonmetastatic Prostate Cancer; $\mathrm{N}=5,182$ )

Alcohol Intake at Diagnosis $(\mathrm{g} / \mathrm{d})$

\begin{tabular}{|c|c|c|c|c|c|}
\hline Characteristic at Diagnosis & None & $>0$ to $<10 \mathrm{~g}$ & 10 to $<15 \mathrm{~g}$ & 15 to $<30 \mathrm{~g}$ & $\geq 30 \mathrm{~g}$ \\
\hline$n^{*}$ & 1,225 & 1,770 & 691 & 923 & 573 \\
\hline Age at diagnosis, years & 70 & 70 & 70 & 70 & 70 \\
\hline White, \% & 90 & 91 & 93 & 95 & 97 \\
\hline $\mathrm{BMI}, \mathrm{kg} / \mathrm{m}^{2}$ & 26.0 & 26.1 & 25.6 & 25.7 & 26.0 \\
\hline Vigorous physical activity, MET-h/wk & 7.5 & 8.4 & 9.8 & 9.3 & 7.6 \\
\hline Family history of prostate cancer, $\%$ & 24 & 21 & 18 & 20 & 22 \\
\hline Current smoker, \% & 3 & 3 & 3 & 3 & 7 \\
\hline History of diabetes, $\%$ & 12 & 10 & 5 & 8 & 6 \\
\hline Total energy intake, $\mathrm{kcal} / \mathrm{d}$ & 1,880 & 1,926 & 1,954 & 2,105 & 2,252 \\
\hline Vegetable fat, g/d & 37.8 & 37.2 & 137.5 & 38.5 & 37.9 \\
\hline Coffee, servings/d & 1.3 & 1.5 & 1.5 & 1.6 & 1.8 \\
\hline Whole milk, servings/d & 0.08 & 0.07 & 0.07 & 0.04 & 0.04 \\
\hline Choline, mg/d & 375 & 382 & 375 & 380 & 356 \\
\hline Lycopene, $\mu \mathrm{g} / \mathrm{d}$ & 665 & 753 & 719 & 771 & 720 \\
\hline Year of diagnosis & 1,999 & 1,999 & 2,000 & 2,000 & 2,000 \\
\hline No. of PSA screenings before diagnosis & 2.3 & 2.4 & 2.4 & 2.9 & 2.6 \\
\hline \multicolumn{6}{|l|}{ TNM stage, \% } \\
\hline $\mathrm{T} 1$ & 48 & 53 & 56 & 59 & 59 \\
\hline $\mathrm{T} 2$ & 35 & 32 & 31 & 30 & 30 \\
\hline T3 & 3 & 3 & 4 & 3 & 2 \\
\hline $\mathrm{T} 4 / \mathrm{N} 1$ & 1 & 1 & 1 & 1 & 1 \\
\hline Missing & 13 & 11 & 8 & 7 & 8 \\
\hline \multicolumn{6}{|l|}{ Gleason grade, \% } \\
\hline$<7$ & 43 & 46 & 46 & 46 & 49 \\
\hline 7 & 30 & 30 & 33 & 33 & 29 \\
\hline$>7$ & 11 & 10 & 9 & 12 & 9 \\
\hline Missing & 16 & 14 & 12 & 9 & 13 \\
\hline \multicolumn{6}{|l|}{ PSA level, \% } \\
\hline$<4$ & 11 & 12 & 10 & 12 & 9 \\
\hline 4 to $<10$ & 47 & 51 & 53 & 56 & 52 \\
\hline 10 to $<20$ & 15 & 16 & 17 & 14 & 17 \\
\hline$\geq 20$ & 8 & 6 & 8 & 6 & 8 \\
\hline Missing & 19 & 15 & 12 & 12 & 14 \\
\hline \multicolumn{6}{|l|}{ Primary treatment, \% } \\
\hline $\mathrm{RP}$ & 40 & 43 & 44 & 45 & 42 \\
\hline Radiation & 30 & 32 & 34 & 34 & 34 \\
\hline Hormones & 5 & 4 & 4 & 4 & 4 \\
\hline Other or active surveillance & 9 & 10 & 10 & 8 & 11 \\
\hline Missing & 16 & 11 & 8 & 9 & 9 \\
\hline
\end{tabular}

NOTE. Data are presented as means unless indicated otherwise.

Abbreviations: BMI, body mass index; PSA, prostate-specific antigen; RP, radical prostatectomy.

*Includes all participants with an alcohol report on the first postdiagnosis questionnaire ( $n=5,097)$. This totals to $<5,182$, the number of participants included in the primary analysis of alcohol intake among men with nonmetastatic prostate cancer (Table 4), because the main analysis includes participants who provided postdiagnosis alcohol information on later questionnaires. 
TABLE 4. Postdiagnosis Alcohol Intake and Progression to Lethal Prostate Cancer and Overall Mortality Among Men Diagnosed Initially With Nonmetastatic Prostate Cancer in Health Professionals Follow-Up Study $(N=5,182)$

Lethal Prostate Cancer

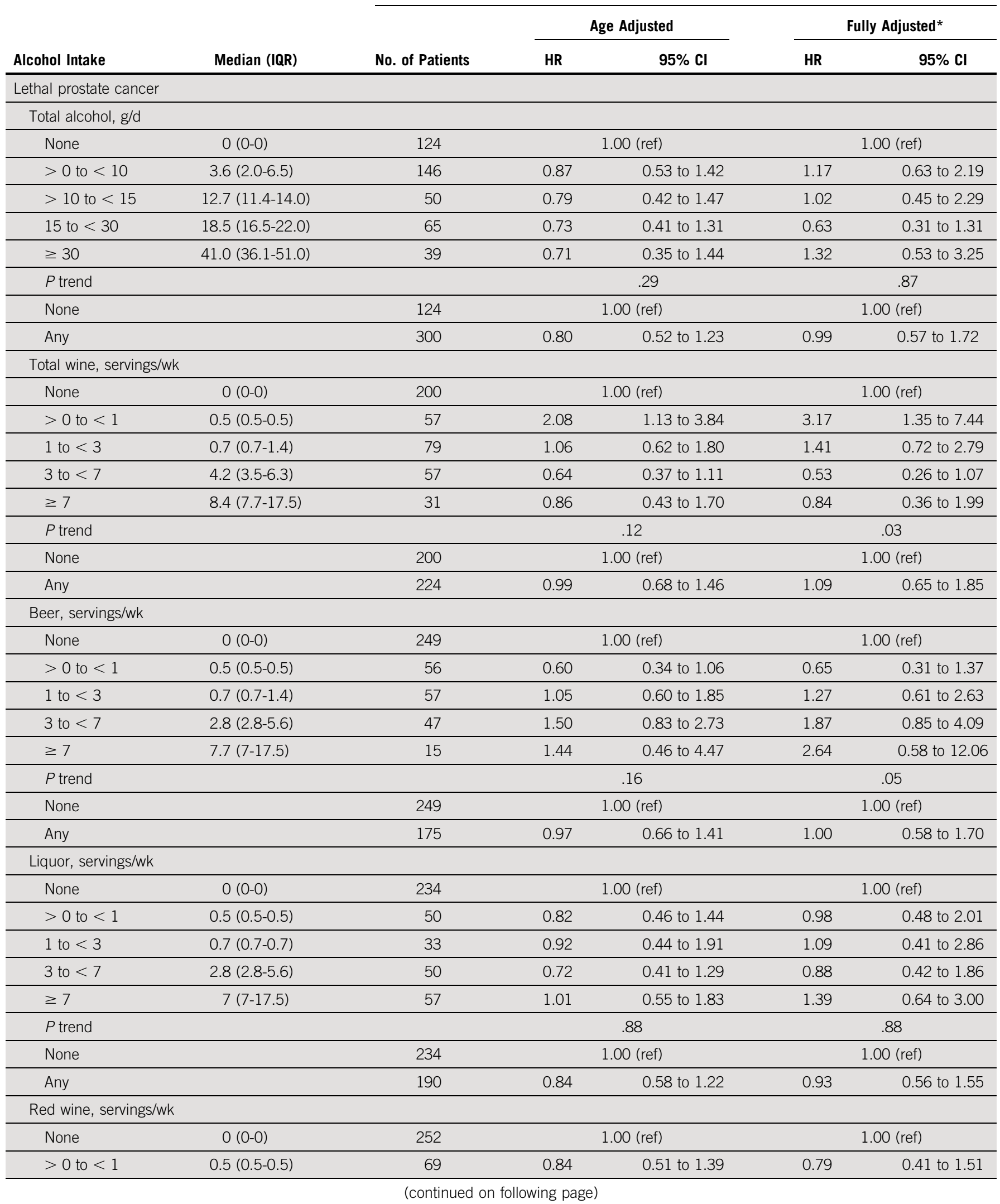


TABLE 4. Postdiagnosis Alcohol Intake and Progression to Lethal Prostate Cancer and Overall Mortality Among Men Diagnosed Initially With Nonmetastatic Prostate Cancer in Health Professionals Follow-Up Study $(N=5,182)$ (continued)

Lethal Prostate Cancer

Age Adjusted

\begin{tabular}{cc} 
Alcohol Intake & Median (IQR) \\
\hline 1 to $<3$ & $0.7(0.7-0.7)$ \\
\hline 3 to $<7$ & $2.8(2.8-2.8)$ \\
\hline$\geq 7$ & $7(7-17.5)$ \\
\hline
\end{tabular}

$P$ trend

None

Any

White wine, servings/wk

$\begin{array}{lcr}\text { None } & 0(0-0) & 243 \\ >0 \text { to }<1 & 0.5(0.5-0.5) & 102 \\ 1 \text { to }<3 & 0.7(0.7-0.7) & 35 \\ 3 \text { to }<7 & 2.8(2.8-2.8) & 35 \\ \geq 7 & 7(7-17.5) & \end{array}$

$P$ trend

None

Any

Overall mortality

\begin{tabular}{lc}
\hline Total alcohol, g/d & \\
\hline None & $0(0-0)$ \\
\hline$>0$ to $<10$ & $3.6(2.0-6.5)$ \\
\hline$>10$ to $<15$ & $12.7(11.4-14.0)$ \\
\hline 15 to $<30$ & $18.5(16.5-22.0)$ \\
\hline$\geq 30$ & $41.0(36.1-51.0)$ \\
\hline$P$ trend & \\
\hline None & \\
\hline Any &
\end{tabular}

\begin{tabular}{cl}
\cline { 2 - 2 } No. of Patients & HR \\
\hline 27 & 0.65 \\
\hline 56 & 0.66 \\
\hline 20 & 0.60 \\
\hline
\end{tabular}

.12

252
172

172

$\begin{array}{rr}243 & \\ 102 & 1.31 \\ 35 & 0.96 \\ 35 & 0.65 \\ 9 & 0.66\end{array}$

0.72

1.00 (ref)

1.00 (ref)

.14

243

181

1.00 (ref)

520

521

521
177

219

157

520
1,074

520
1,074

520

95\% C

0.31 to 1.39
0.39 to 1.13
0.26 to 1.39

0.49 to 1.05

0.79 to 2.18

0.51 to 1.84

0.35 to 1.20

0.22 to 1.96

$0.95 \quad 0.65$ to 1.39

$$
0(0-0)
$$

864

864

$0.7(0.7-1.4)$

1 to $<3$

$4.2(3.5-6.3)$

$\geq 7$

$8.4(7.7-17.5)$

$P$ trend

None

Any

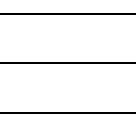

864

302

179

114

864

730

$$
0(0-0)
$$

$0.5(0.5-0.5)$

$0.7(0.7-1.4)$

$2.8(2.8-5.6)$

Fully Adjusted*

\begin{tabular}{lc}
\hline HR & 95\% $\mathbf{~ I ~}$ \\
\hline 0.46 & 0.17 to 1.25 \\
\hline 0.49 & 0.25 to 0.97 \\
\hline 0.51 & 0.18 to 1.40 \\
\hline & .05 \\
\hline 0.50 & 0.00 (ref) \\
\hline \multicolumn{2}{c}{1.00 (ref) 0.86} \\
\hline 1.76 & 0.92 to 3.34 \\
\hline 1.00 & 0.44 to 2.29 \\
\hline 0.53 & 0.24 to 1.15 \\
\hline 0.69 & 0.17 to 2.77 \\
\hline & .12 \\
\hline 1.25 & 0.73 to 2.15 \\
\hline
\end{tabular}


TABLE 4. Postdiagnosis Alcohol Intake and Progression to Lethal Prostate Cancer and Overall Mortality Among Men Diagnosed Initially With Nonmetastatic Prostate Cancer in Health Professionals Follow-Up Study $(\mathrm{N}=5,182)$ (continued)

Lethal Prostate Cancer

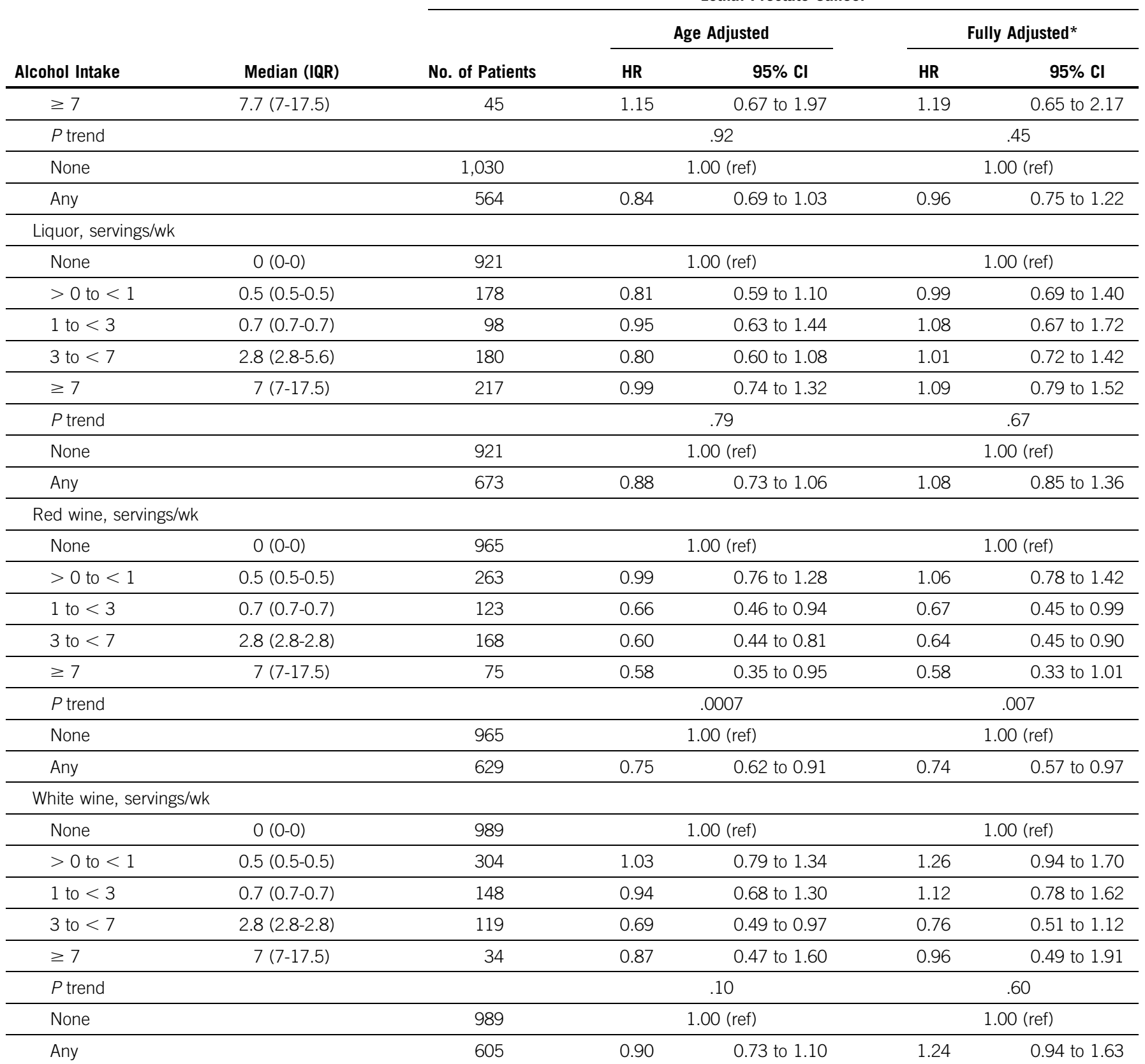

Abbreviations: HR, hazard ratio; IQR, interquartile range.

*Adjusted for energy intake (kilocalories/day); smoking status (never, past [quit $>10$ years ago], past [quit $\leq 10$ years ago], current [ $<40$ pack-years], current [ $\geq 40$ pack-years]; body mass index ( $\mathrm{kg} / \mathrm{m}^{2}:<25,25$ to $<30, \geq 30$ ); vigorous physical activity ( $<3 \mathrm{~h} / \mathrm{wk}, \geq 3 \mathrm{~h} / \mathrm{wk}$ ); coffee intake (servings/day, quintiles); diabetes (yes or no); primary treatment (radical prostatectomy, radiation, hormones, other, missing); stage at diagnosis (T1, T2, T3+, missing); Gleason grade at diagnosis ( $<7,7,>7$, missing); prostate-specific antigen at diagnosis (ng/dL; $<4,4$ to $<10,10$ to $<20$, $\geq 20$, missing); prostate-specific antigen screening (screening on the cycle before prostate cancer diagnosis was reported [yes or no] and intensity of screening [ $\geq 50 \%$ of previous cycles, yes or no]); diabetes (yes or no). Beer, wine, and liquor mutually adjusted for each other. Red wine and white wine were also mutually adjusted. Models for allcause mortality also adjusted for parental history of myocardial infarction before 60 years of age (yes or no); comorbidities (yes or no; yes if myocardial infarction, angina, coronary artery bypass or angioplasty, stroke, emphysema or chronic obstructive pulmonary disease, or Parkinson's disease); high blood pressure (yes or no); and high cholesterol (yes or no). 
alcohol intake from before to after diagnosis was not associated with risk of either outcome (Appendix Table A7, online only). Among drinkers, the frequency of alcohol intake was not associated with either outcome, and there were no interactions between amount and frequency (results not shown).

\section{DISCUSSION}

In this prospective cohort study with 26 years of follow-up among 47,568 men in the United States, alcohol intake was associated with a lower risk of lethal prostate cancer, but there was no dose-response relationship. No specific alcohol subtype seemed to be driving this association. Among the 5,182 men diagnosed with nonmetastatic prostate cancer, red wine after diagnosis was associated with a lower risk of lethal prostate cancer and overall mortality, with a doseresponse relationship for both outcomes.

Our data support the possibility that alcohol intake, particularly red wine, may inhibit prostate cancer progression. There are several plausible biologic mechanisms to explain these inverse associations. Alcohol may increase sex hormonebinding globulin levels ${ }^{23}$ and lower testosterone,${ }^{24-27}$ which may reduce hormonal promotion of prostate tumor growth later in disease progression. Alcohol intake may also be associated with lower insulin-like growth factor-1, 28,29 a wellestablished risk factor for advanced prostate cancer. Randomized controlled trials indicate that wine improves insulin metabolism and increases antioxidant status, ${ }^{30}$ pathways thought to play an important role in prostate cancer progression. Red wine may also lower inflammation, because it has been associated with decreased circulating soluble inflammatory mediators levels, including plasma fibrinogen and interleukin- $1 \alpha$, decreased C-reactive protein levels, and decreased monocyte and endothelial adhesion molecules. ${ }^{31,32}$ In addition, studies examining the potential effects of wine polyphenols on prostate cancer cells have reported inhibition of tumor growth, migration, and invasiveness. ${ }^{33-47}$

Our data also support the possibility that moderate alcohol intake is associated with a lower risk of overall mortality among patients with prostate cancer. These findings align with epidemiologic data that consistently indicate that moderate alcohol is associated with a lower risk of

\footnotetext{
AFFILIATIONS

${ }^{1}$ Harvard T.H. Chan School of Public Health, Boston, MA

${ }^{2}$ Brigham and Women's Hospital and Harvard Medical School, Boston, MA

${ }^{3}$ University of California, San Francisco, San Francisco, CA
}

\section{CORRESPONDING AUTHOR}

Mary K. Downer, PhD, SM, Harvard T.H. Chan School of Public Health, Department of Epidemiology, 9th Floor, 677 Huntington Ave, Boston, MA 02115; e-mail: downerma@gmail.com. cardiovascular disease, ischemic stroke, diabetes, and overall mortality. ${ }^{4}$ However, we observed no benefit of beer or liquor on overall mortality among men with prostate cancer. This is in contrast to studies focused on cardiovascular disease, which have demonstrated a benefit from alcohol itself, regardless of source. ${ }^{48}$

Our results should be interpreted conservatively. First, the lack of a dose-response relationship for total alcohol casts doubt on a causal interpretation of our findings. Second, our red wine findings could partly be a result of unmeasured confounding; health-conscious characteristics of red wine drinkers may reduce the risk of prostate cancer death. However, the results in all analyses were qualitatively unchanged when adjusting for known and potential clinical, demographic, and lifestyle risk factors and screening behavior, and the results were essentially unchanged when restricting to never-smokers. Third, reverse causation cannot be ruled out, particularly in the analysis of men with nonmetastatic prostate cancer. Here, our results were attenuated when we used the first postdiagnostic questionnaire (completed 6.3 years before death as a result of prostate cancer, on average) and when lagging our alcohol exposures, although we had limited power.

The strengths of our study include multiple, validated, and prospective exposure and covariates, detailed clinical data, complete and long follow-up, a large number of events, and clinically relevant end points. Our study also has limitations. It is possible that unmeasured confounding affected the observed associations. Alcohol intake was self-reported. However, validation studies have shown that exposure measurement error is small, and measurement error is expected to be nondifferential because of our prospective assessments. Last, our homogenous study population limits generalizability to other racial and ethnic populations but reduces confounding by sociodemographic factors.

We conclude that moderate alcohol intake is not associated with a higher risk of being diagnosed with lethal prostate cancer. Our results indicate that moderate alcohol intake among men with prostate cancer is not associated with a higher risk of progression to lethal disease or overall mortality. The potential benefit of red wine on prostate cancer progression merits additional research.

\section{PRIOR PRESENTATION}

Presented as an abstract at the Western Section American Urology Association Conference, Maui, HI, October 28-November 2, 2018; the Prostate Cancer Foundation Retreat, Washington DC, October 5-7, 2017; and the Celebration of Jr. Investigators in Cancer Research, Dana Farber/ Harvard Cancer Center, Boston, MA, November 6, 2017.

\section{SUPPORT}

Supported by the Prostate Cancer Foundation and by National Cancer Institute Grants CA34944, CA40360, CA141298, CA167552, HL26490, HL34595, and UM1 CA167552. 
AUTHORS' DISCLOSURES OF POTENTIAL CONFLICTS OF INTEREST AND DATA AVAILABILITY STATEMENT

Disclosures provided by the authors and data availability statement (if applicable) are available with this article at DOI https://doi.org/10.1200/ JCO.18.02462.

\section{AUTHOR CONTRIBUTIONS}

Conception and design: Mary K. Downer, Meir J. Stampfer, Edward L. Giovannucci, Walter C. Willett, Erin L. Van Blarigan

Financial support: Meir J. Stampfer, Eric B. Rimm, Lorelei A. Mucci Administrative support: Meir J. Stampfer, Lorelei A. Mucci, Walter C. Willett

Provision of study material or patients: Meir J. Stampfer, Eric B. Rimm, Lorelei A. Mucci

Collection and assembly of data: Meir J. Stampfer, Kathryn M. Wilson, Edward L. Giovannucci, Eric B. Rimm, Walter C. Willett
Data analysis and interpretation: Mary K. Downer, Stacey A. Kenfield, Meir J. Stampfer, Barbra A. Dickerman, Edward L. Giovannucci, Molin Wang, Lorelei A. Mucci, Walter C. Willett, June M. Chan, Erin L. Van Blarigan Manuscript writing: All authors

Final approval of manuscript: All authors

Accountable for all aspects of the work: All authors

\section{ACKNOWLEDGMENT}

We thank the participants and staff of the Health Professionals Follow-up Study for their valuable contributions. We also thank the following state cancer registries for their help: Alabama, Arizona, Arkansas, California, Colorado, Connecticut, Delaware, Florida, Georgia, Idaho, Illinois, Indiana, lowa, Kentucky, Louisiana, Maine, Maryland, Massachusetts, Michigan, Nevada, New Hampshire, New Jersey, New York, North Carolina, North Dakota, Ohio, Oklahoma, Oregon, Pennsylvania, Rhode Island, South Carolina, Tennessee, Texas, Virginia, Washington, and Wyoming.

\section{REFERENCES}

1. American Cancer Society: Key Statistics for Prostate Cancer, 2017. https://www.cancer.org/cancer/prostate-cancer/about/key-statistics.html

2. National Cancer Institute Surveillance, Epidemiology, and End Results Program: Cancer stat facts: Prostate cancer. seer.cancer.gov/statfacts/html/prost.html

3. Thun MJ, Peto R, Lopez AD, et al: Alcohol consumption and mortality among middle-aged and elderly U.S. adults. N Engl J Med 337:1705-1714, 1997

4. National Institute on Alcohol Abuse and Alcoholism: Alcohol facts and statistics. http://www.niaaa.nih.gov/alcohol-health/overview-alcohol-consumption/ alcohol-facts-and-statistics

5. LoConte NK, Brewster AM, Kaur JS, et al: Alcohol and cancer: A statement of the American Society of Clinical Oncology. J Clin Oncol 36:83-93, 2018

6. Dickerman BA, Markt SC, Koskenvuo M, et al: Alcohol intake, drinking patterns, and prostate cancer risk and mortality: A 30-year prospective cohort study of Finnish twins. Cancer Causes Control 27:1049-1058, 2016

7. Platz EA, Leitzmann MF, Rimm EB, et al: Alcohol intake, drinking patterns, and risk of prostate cancer in a large prospective cohort study. Am J Epidemiol 159 : 444-453, 2004

8. Rota M, Scotti L, Turati F, et al: Alcohol consumption and prostate cancer risk: A meta-analysis of the dose-risk relation. Eur J Cancer Prev 21:350-359, 2012

9. Bagnardi V, Rota M, Botteri E, et al: Alcohol consumption and site-specific cancer risk: A comprehensive dose-response meta-analysis. Br J Cancer 112 : 580-593, 2015

10. Crispo A, Talamini R, Gallus S, et al: Alcohol and the risk of prostate cancer and benign prostatic hyperplasia. Urology 64:717-722, 2004

11. Albertsen K, Grønbaek M: Does amount or type of alcohol influence the risk of prostate cancer? Prostate 52:297-304, 2002

12. Sutcliffe S, Giovannucci E, Leitzmann MF, et al: A prospective cohort study of red wine consumption and risk of prostate cancer. Int J Cancer 120:1529-1535, 2007

13. Chao C, Haque R, Van Den Eeden SK, et al: Red wine consumption and risk of prostate cancer: The California Men's Health Study. Int J Cancer 126:171-179, 2010

14. Sesso HD, Paffenbarger RS Jr, Lee IM: Alcohol consumption and risk of prostate cancer: The Harvard Alumni Health Study. Int J Epidemiol 30:749-755, 2001

15. Schoonen WM, Salinas CA, Kiemeney LA, et al: Alcohol consumption and risk of prostate cancer in middle-aged men. Int J Cancer 113:133-140, 2005

16. Papa NP, Maclnnis RJ, Jayasekara H, et al: Total and beverage-specific alcohol intake and the risk of aggressive prostate cancer: A case-control study. Prostate Cancer Prostatic Dis 20:305-310, 2017

17. Baglietto L, Severi G, English DR, et al: Alcohol consumption and prostate cancer risk: Results from the Melbourne Collaborative Cohort Study. Int J Cancer 119 : $1501-1504,2006$

18. Watters JL, Park Y, Hollenbeck A, et al: Alcoholic beverages and prostate cancer in a prospective US cohort study. Am J Epidemiol 172:773-780, 2010

19. Rimm EB, Giovannucci EL, Stampfer MJ, et al: Reproducibility and validity of an expanded self-administered semiquantitative food frequency questionnaire among male health professionals. Am J Epidemiol 135:1114-1126, discussion 1127-1136, 1992

20. Feskanich D, Rimm EB, Giovannucci EL, et al: Reproducibility and validity of food intake measurements from a semiquantitative food frequency questionnaire. J Am Diet Assoc 93:790-796, 1993

21. Giovannucci E, Colditz G, Stampfer M, et al: The Assessment of Alcohol Consumption by a Simple Self-Administered Questionnaire. Am J Epidimiol 133:810817,1991

22. Stampfer MJ, Willett WC, Speizer FE, et al: Test of the National Death Index. Am J Epidemiol 119:837-839, 1984

23. Iturriaga H, Lioi X, Valladares L: Sex hormone-binding globulin in non-cirrhotic alcoholic patients during early withdrawal and after longer abstinence. Alcohol Alcohol 34:903-909, 1999

24. Green GR: Mechanism of hypogonadism in cirrhotic males. Gut 18:843-853, 1977

25. Gordon GG, Altman K, Southren AL, et al: Effect of alcohol (ethanol) administration on sex-hormone metabolism in normal men. N Engl J Med 295:793-797, 1976

26. Mendelson JH, Mello NK, Ellingboe J: Effects of acute alcohol intake on pituitary-gonadal hormones in normal human males. J Pharmacol Exp Ther 202: 676-682, 1977

27. Ida Y, Tsujimaru S, Nakamaura K, et al: Effects of acute and repeated alcohol ingestion on hypothalamic-pituitary-gonadal and hypothalamic-pituitary-adrenal functioning in normal males. Drug Alcohol Depend 31:57-64, 1992

28. Santolaria F, González-González G, González-Reimers E, et al: Effects of alcohol and liver cirrhosis on the GH-IGF-I axis. Alcohol Alcohol 30:703-708, 1995

29. Teramukai S, Rohan T, Eguchi H, et al: Anthropometric and behavioral correlates of insulin-like growth factor I and insulin-like growth factor binding protein 3 in middle-aged Japanese men. Am J Epidemiol 156:344-348, 2002 
30. Chiva-Blanch G, Urpi-Sarda M, Ros E, et al: Effects of red wine polyphenols and alcohol on glucose metabolism and the lipid profile: A randomized clinical trial. Clin Nutr 32:200-206, 2013

31. Estruch R, Sacanella E, Badia E, et al: Different effects of red wine and gin consumption on inflammatory biomarkers of atherosclerosis: A prospective randomized crossover trial. Effects of wine on inflammatory markers. Atherosclerosis 175:117-123, 2004

32. Chiva-Blanch G, Urpi-Sarda M, Llorach R, et al: Differential effects of polyphenols and alcohol of red wine on the expression of adhesion molecules and inflammatory cytokines related to atherosclerosis: A randomized clinical trial. Am J Clin Nutr 95:326-334, 2012

33. Dias SJ, Li K, Rimando AM, et al: Trimethoxy-resveratrol and piceatannol administered orally suppress and inhibit tumor formation and growth in prostate cancer xenografts. Prostate 73:1135-1146, 2013

34. Sheth S, Jajoo S, Kaur T, et al: Resveratrol reduces prostate cancer growth and metastasis by inhibiting the Akt/MicroRNA-21 pathway. PLoS One 7:e51655, 2012

35. Hsieh TC, Huang YC, Wu JM: Control of prostate cell growth, DNA damage and repair and gene expression by resveratrol analogues, in vitro. Carcinogenesis 32: 93-101, 2011

36. Wang Y, Romigh T, He X, et al: Resveratrol regulates the PTEN/AKT pathway through androgen receptor-dependent and -independent mechanisms in prostate cancer cell lines. Hum Mol Genet 19:4319-4329, 2010

37. Kai L, Samuel SK, Levenson AS: Resveratrol enhances p53 acetylation and apoptosis in prostate cancer by inhibiting MTA1/NuRD complex. Int J Cancer 126: $1538-1548,2010$

38. Chen Q, Ganapathy S, Singh KP, et al: Resveratrol induces growth arrest and apoptosis through activation of FOXO transcription factors in prostate cancer cells. PLoS One 5:e15288, 2010

39. Benitez DA, Hermoso MA, Pozo-Guisado E, et al: Regulation of cell survival by resveratrol involves inhibition of NF kappa B-regulated gene expression in prostate cancer cells. Prostate 69:1045-1054, 2009

40. Horvath Z, Marihart-Fazekas S, Saiko P, et al: Novel resveratrol derivatives induce apoptosis and cause cell cycle arrest in prostate cancer cell lines. Anticancer Res 27(5A):3459-3464, 2007

41. Kuwajerwala N, Cifuentes E, Gautam S, et al: Resveratrol induces prostate cancer cell entry into s phase and inhibits DNA synthesis. Cancer Res 62:2488-2492, 2002

42. Jones SB, DePrimo SE, Whitfield ML, et al: Resveratrol-induced gene expression profiles in human prostate cancer cells. Cancer Epidemiol Biomarkers Prev 14: 596-604, 2005

43. Shi WF, Leong M, Cho E, et al: Repressive effects of resveratrol on androgen receptor transcriptional activity. PLoS One 4:e7398, 2009

44. Mitchell SH, Zhu W, Young CY: Resveratrol inhibits the expression and function of the androgen receptor in LNCaP prostate cancer cells. Cancer Res 59: 5892-5895, 1999

45. Streicher W, Luedeke M, Azoitei A, et al: Stilbene induced inhibition of androgen receptor dimerization: Implications for AR and ARALBD-signalling in human prostate cancer cells. PLoS One 9:e98566, 2014

46. Fraser SP, Peters A, Fleming-Jones S, et al: Resveratrol: Inhibitory effects on metastatic cell behaviors and voltage-gated $\mathrm{Na}^{+}$channel activity in rat prostate cancer in vitro. Nutr Cancer 66:1047-1058, 2014

47. Lall RK, Syed DN, Adhami VM, et al: Dietary polyphenols in prevention and treatment of prostate cancer. Int J Mol Sci 16:3350-3376, 2015

48. Mukamal KJ, Conigrave KM, Mittleman MA, et al: Roles of drinking pattern and type of alcohol consumed in coronary heart disease in men. N Engl J Med 348: $109-118,2003$

\section{Publish Your Research With Confidence With ASCO and Editage}

ASCO has partnered with Editage to provide members and authors with expert manuscript preparation services that support you through every stage of your academic journey.

Learn more at https://asco.editage.com

ASCO Journals 
AUTHORS' DISCLOSURES OF POTENTIAL CONFLICTS OF INTEREST AND DATA AVAILABILITY STATEMENT

\section{Alcohol Intake and Risk of Lethal Prostate Cancer in the Health Professionals Follow-Up Study}

The following represents disclosure information provided by authors of this manuscript. All relationships are considered compensated. Relationships are self-held unless noted. I = Immediate Family Member, Inst = My Institution. Relationships may not relate to the subject matter of this manuscript. For more information about ASCO's conflict of interest policy, please refer to www.asco.org/rwc or ascopubs.org/jco/site/ifc.

Mary K. Downer

Employment: Genentech/Roche

Stock and Other Ownership Interests: Genentech/Roche

Travel, Accommodations, Expenses: Genentech/Roche

Stacey A. Kenfield

Research Funding: GenomeDx

Meir J. Stampfer

Stock and Other Ownership Interests: Elysium

Consulting or Advisory Role: Elysium
Barbra A. Dickerman

Research Funding: ASISA

June M. Chan

Employment: GRAIL (I), Myriad Genetics (I)

Stock and Other Ownership Interests: GRAIL (I)

Research Funding: GRAIL (I), Genomic Health (Inst), GenomeDx, Myriad Genetics (Inst)

Travel, Accommodations, Expenses: GRAIL (I), Myriad Genetics (I)

No other potential conflicts of interest were reported. 
TABLE A1. Risk Sensitivity Analyses: Alcohol Intake and Risk of Lethal Prostate Cancer Among Participants in the Health Professionals Follow-Up Study

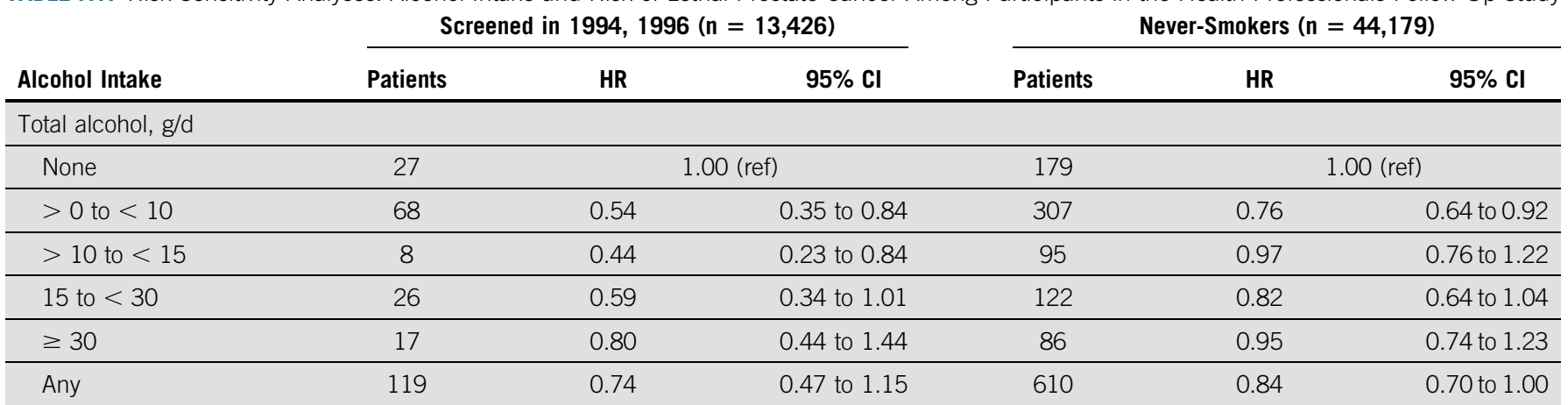

Total wine, servings/wk

\begin{tabular}{|c|c|c|c|c|c|c|}
\hline \multirow{2}{*}{$\begin{array}{l}\text { None } \\
>0 \text { to }<1\end{array}$} & \multirow{2}{*}{$\begin{array}{l}38 \\
43\end{array}$} & \multicolumn{2}{|c|}{1.00 (ref) } & \multirow{2}{*}{$\begin{array}{l}294 \\
167\end{array}$} & \multicolumn{2}{|c|}{1.00 (ref) } \\
\hline & & 0.96 & 0.60 to 1.53 & & 0.87 & 0.71 to 1.06 \\
\hline 1 to $<3$ & 45 & 1.16 & 0.72 to 1.89 & 186 & 1.00 & 0.82 to 1.21 \\
\hline$\geq 7$ & 7 & 0.87 & 0.37 to 2.00 & 37 & 0.94 & 0.66 to 1.34 \\
\hline Any & 108 & 1.10 & 0.70 to 1.71 & 495 & 1.00 & 0.84 to 1.19 \\
\hline None & 60 & \multicolumn{2}{|c|}{1.00 (ref) } & 340 & \multicolumn{2}{|c|}{1.00 (ref) } \\
\hline$>0$ to $<1$ & 41 & 0.66 & 0.42 to 1.01 & 195 & 0.86 & 0.71 to 1.04 \\
\hline 1 to $<3$ & 20 & 0.56 & 0.32 to 0.99 & 101 & 0.80 & 0.63 to 1.02 \\
\hline 3 to $<7$ & 14 & 0.73 & 0.38 to 1.42 & 107 & 1.08 & 0.85 to 1.37 \\
\hline None & 58 & \multicolumn{2}{|c|}{1.00 (ref) } & 336 & \multicolumn{2}{|c|}{1.00 (ref) } \\
\hline$>0$ to $<1$ & 33 & 0.86 & 0.55 to 1.36 & 147 & 0.81 & 0.66 to 0.99 \\
\hline 1 to $<3$ & 14 & 0.69 & 0.38 to 1.24 & 86 & 0.82 & 0.64 to 1.05 \\
\hline 3 to $<7$ & 21 & 0.94 & 0.54 to 1.65 & 121 & 0.87 & 0.70 to 1.09 \\
\hline$\geq 7$ & 20 & 1.00 & 0.56 to 1.79 & 99 & 0.88 & 0.70 to 1.12 \\
\hline Any & 88 & 0.85 & 0.56 to 1.29 & 453 & 0.90 & 0.76 to 1.07 \\
\hline \multicolumn{7}{|c|}{ Red wine, servings/wk } \\
\hline None & 58 & \multicolumn{2}{|c|}{1.00 (ref) } & 403 & \multicolumn{2}{|c|}{1.00 (ref) } \\
\hline$>0$ to $<1$ & 50 & 0.91 & 0.60 to 1.38 & 212 & 0.88 & 0.74 to 1.05 \\
\hline$>0$ to $<1$ & 64 & 0.99 & 0.65 to 1.52 & 244 & 0.85 & 0.71 to 1.01 \\
\hline \multicolumn{7}{|c|}{ (continued on following page) } \\
\hline
\end{tabular}


TABLE A1. Risk Sensitivity Analyses: Alcohol Intake and Risk of Lethal Prostate Cancer Among Participants in the Health Professionals Follow-Up Study (continued)

Screened in 1994, $1996(n=13,426)$

\begin{tabular}{cccc} 
Alcohol Intake & Patients & HR & 95\% $\mathbf{~ l ~}$ \\
\hline 1 to $<3$ & 29 & 1.03 & 0.61 to 1.74 \\
\hline 3 to $<7$ & 10 & 0.97 & 0.46 to 2.04 \\
\hline$\geq 7$ & 0 & 0.47 & 0.09 to 2.38 \\
\hline Any & 103 & 1.10 & 0.68 to 1.78
\end{tabular}

Excluded Men Who Reported Decreased Alcohol at Baseline* $(n=29,057)$

\begin{tabular}{|c|c|c|c|c|c|c|}
\hline Alcohol Intake & Patients & HR & $95 \% \mathrm{Cl}$ & Patients & HR & $95 \% \mathrm{Cl}$ \\
\hline None & 67 & \multicolumn{2}{|c|}{1.00 (ref) } & 193 & \multicolumn{2}{|c|}{1.00 (ref) } \\
\hline$>10$ to $<15$ & 74 & 1.23 & 0.90 to 1.67 & 103 & 0.82 & 0.64 to 1.05 \\
\hline 15 to $<30$ & 107 & 1.03 & 0.75 to 1.40 & 130 & 0.88 & 0.70 to 1.11 \\
\hline Any & 434 & 1.04 & 0.79 to 1.38 & 676 & 0.84 & 0.71 to 0.99 \\
\hline \multicolumn{7}{|c|}{ Total wine, servings/wk } \\
\hline None & 151 & \multicolumn{2}{|c|}{1.00 (ref) } & 328 & \multicolumn{2}{|c|}{1.00 (ref) } \\
\hline$>0$ to $<1$ & 96 & 0.95 & 0.73 to 1.25 & 181 & 0.87 & 0.72 to 1.05 \\
\hline Any & 350 & 1.10 & 0.87 to 1.37 & 541 & 0.98 & 0.83 to 1.15 \\
\hline \multicolumn{7}{|l|}{ Beer, servings/wk } \\
\hline None & 163 & \multicolumn{2}{|c|}{1.00 (ref) } & 368 & \multicolumn{2}{|c|}{1.00 (ref) } \\
\hline$>0$ to $<1$ & 138 & 1.08 & 0.85 to 1.37 & 218 & 0.89 & 0.75 to 1.07 \\
\hline 1 to $<3$ & 76 & 0.98 & 0.73 to 1.32 & 116 & 0.88 & 0.70 to 1.09 \\
\hline 3 to $<7$ & 81 & 1.21 & 0.90 to 1.61 & 113 & 1.07 & 0.85 to 1.34 \\
\hline$\geq 7$ & 43 & 1.15 & 0.81 to 1.65 & 54 & 1.08 & 0.80 to 1.46 \\
\hline Any & 338 & 1.14 & 0.91 to 1.42 & 501 & 0.99 & 0.84 to 1.16 \\
\hline \multicolumn{7}{|c|}{ Liquor, servings/wk } \\
\hline \multicolumn{7}{|c|}{ Red wine, servings/wk } \\
\hline None & 217 & \multicolumn{2}{|c|}{1.00 (ref) } & 446 & \multicolumn{2}{|c|}{1.00 (ref) } \\
\hline$>0$ to $<1$ & 142 & 0.98 & 0.78 to 1.22 & 233 & 0.89 & 0.75 to 1.05 \\
\hline 1 to $<3$ & 85 & 1.31 & 1.00 to 1.71 & 121 & 1.16 & 0.93 to 1.44 \\
\hline 3 to $<7$ & 44 & 1.29 & 0.92 to 1.82 & 54 & 1.08 & 0.81 to 1.46 \\
\hline$\geq 7$ & 13 & 1.13 & 0.63 to 2.02 & 15 & 1.03 & 0.61 to 1.76 \\
\hline
\end{tabular}

Never-Smokers $(n=44,179)$

\begin{tabular}{ccc}
\hline Patients & HR & $\mathbf{9 5 \%} \mathbf{~ C l}$ \\
\hline 131 & 1.08 & 0.87 to 1.34 \\
\hline 82 & 1.08 & 0.84 to 1.40 \\
\hline 9 & 0.44 & 0.22 to 0.86 \\
\hline 466 & 0.95 & 0.79 to 1.15
\end{tabular}

Alcohol Value From Most Recent Questionnaire Instead of Cumulative Average $(n=47,568)$ 
TABLE A1. Risk Sensitivity Analyses: Alcohol Intake and Risk of Lethal Prostate Cancer Among Participants in the Health Professionals Follow-Up Study (continued)

Excluded Men Who Reported Decreased Alcohol

\begin{tabular}{l} 
Alcohol Intake \\
\hline Any \\
\hline White wine, servings/wk \\
\hline None \\
\hline$>0$ to $<1$ \\
\hline 1 to $<3$ \\
\hline 3 to $<7$ \\
$\geq 7$ \\
\hline Any
\end{tabular}

Alcohol Intake Updated After Prostate Cancer Diagnosis* $(n=47,568)$

\section{Alcohol Intake}

Total alcohol, g/d

\begin{tabular}{ll}
\hline None & 193 \\
\hline$>0$ to $<10$ & 337 \\
\hline$>10$ to $<15$ & 103 \\
\hline 15 to $<30$ & 130 \\
\hline$\geq 30$ & 106 \\
\hline Any & 676
\end{tabular}

Patients

HR

$95 \% \mathrm{CI}$

Total wine, servings/wk

\begin{tabular}{|c|c|c|c|}
\hline None & 328 & & 0 (ref) \\
\hline$>0$ to $<1$ & 181 & 0.87 & 0.72 to 1.05 \\
\hline 1 to $<3$ & 201 & 0.98 & 0.82 to 1.18 \\
\hline$\geq 7$ & 41 & 0.96 & 0.69 to 1.35 \\
\hline Any & 541 & 0.98 & 0.83 to 1.15 \\
\hline None & 368 & \multicolumn{2}{|c|}{1.00 (ref) } \\
\hline$>0$ to $<1$ & 218 & 0.89 & 0.75 to 1.07 \\
\hline 1 to $<3$ & 116 & 0.88 & 0.70 to 1.09 \\
\hline 3 to $<7$ & 113 & 1.07 & 0.85 to 1.34 \\
\hline$\geq 7$ & 54 & 1.08 & 0.80 to 1.46 \\
\hline$>0$ to $<1$ & 165 & 0.87 & 0.72 to 1.06 \\
\hline 1 to $<3$ & 95 & 0.86 & 0.68 to 1.09 \\
\hline 3 to $<7$ & 139 & 0.95 & 0.77 to 1.17 \\
\hline$\geq 7$ & 115 & 0.89 & 0.71 to 1.12 \\
\hline
\end{tabular}
at Baseline* $(n=29,057)$ Cumulative Average $(n=47,568)$

\begin{tabular}{|c|c|c|c|c|c|}
\hline atients & HR & $95 \% \mathrm{Cl}$ & Patients & HR & $95 \% \mathrm{CI}$ \\
\hline 284 & 1.20 & 0.95 to 1.51 & 423 & 1.06 & 0.89 to 1.26 \\
\hline 177 & & & 360 & & (ref) \\
\hline 157 & 0.88 & 0.70 to 1.10 & 271 & 0.86 & 0.73 to 1.01 \\
\hline 87 & 1.04 & 0.79 to 1.37 & 137 & 1.04 & 0.85 to 1.29 \\
\hline 71 & 1.24 & 0.92 to 1.66 & 91 & 1.11 & 0.87 to 1.41 \\
\hline 9 & 0.52 & 0.26 to 1.02 & 10 & 0.45 & 0.24 to 0.85 \\
\hline 324 & 0.87 & 0.68 to 1.11 & 509 & 0.93 & 0.77 to 1.11 \\
\hline
\end{tabular}

Alcohol Value From Most Recent Questionnaire Instead of 
TABLE A1. Risk Sensitivity Analyses: Alcohol Intake and Risk of Lethal Prostate Cancer Among Participants in the Health Professionals Follow-Up Study (continued)

Alcohol Intake Updated After Prostate Cancer Diagnosis*

$(n=47,568)$

\begin{tabular}{lccc} 
Alcohol Intake & Patients & HR & 95\% $\mathbf{~ I ~}$ \\
\hline Any & 514 & 0.96 & 0.81 to 1.12 \\
\hline Red wine, servings/wk & & & \\
\hline None & 446 & 1.00 (ref) \\
\hline$>0$ to $<1$ & 233 & 0.89 & 0.75 to 1.05 \\
\hline 1 to $<3$ & 121 & 1.16 & 0.93 to 1.44 \\
\hline 3 to $<7$ & 54 & 1.08 & 0.81 to 1.46 \\
\hline$\geq 7$ & 15 & 1.03 & 0.61 to 1.76 \\
\hline Any & 423 & 1.06 & 0.89 to 1.26 \\
\hline White wine, servings/wk & & & \\
\hline None & 360 & & 1.00 (ref) \\
\hline$>0$ to $<1$ & 271 & 0.86 & 0.73 to 1.01 \\
\hline 1 to $<3$ & 137 & 1.04 & 0.85 to 1.29 \\
\hline 3 to $<7$ & 91 & 1.11 & 0.87 to 1.41 \\
\hline$\geq 7$ & 10 & 0.45 & 0.24 to 0.85 \\
\hline Any & 509 & 0.93 & 0.77 to 1.11
\end{tabular}

Abbreviation: HR, hazard ratio.

*Adjusted for energy intake (kilocalories/day); age at diagnosis (years); smoking status (current, past, never); body mass index (kg/m²: $<25,25$ to $<30, \geq$ 30); vigorous physical activity ( $<3$ or $\geq 3 \mathrm{~h} / \mathrm{wk}$ ); primary treatment (radical prostatectomy, radiation, hormones, other, missing); stage at diagnosis ( $\mathrm{T} 1$, $\mathrm{T} 2$, $\mathrm{T} 3+$, missing); Gleason grade at diagnosis ( $<7,7,>7$, missing); prostate-specific antigen at diagnosis (ng/dL: $<4,4$ to $<10,10$ to $<20, \geq 20$, missing); prostate-specific antigen screening (screening on the cycle before prostate cancer diagnosis was reported [yes or no] and intensity of screening [ $\geq 50 \%$ of previous cycles, yes or no]). Beer, wine, and liquor mutually adjusted for each other. Red wine and white wine also mutually adjusted. Models for all-cause mortality also adjusted for parental history of myocardial infarction before 60 years of age (yes or no); comorbidities (yes or no; yes if myocardial infarction, angina, coronary artery bypass or angioplasty, stroke, emphysema or chronic obstructive pulmonary disease, or Parkinson's disease); high blood pressure (yes or no); and high cholesterol (yes or no). 
TABLE A2. Lagged Analysis of Alcohol Intake Among Men at Risk of Prostate Cancer: Alcohol Intake and Risk of Lethal Prostate Cancer Among Participants in the Health Professionals Follow-Up Study

\begin{tabular}{|c|c|c|c|c|c|c|c|c|c|}
\hline \multirow[b]{2}{*}{ Alcohol Intake } & \multicolumn{3}{|c|}{ 2- to 4-Year Lag $(n=47,199)$} & \multicolumn{3}{|c|}{ 4- to 6-Year Lag $(n=46,563)$} & \multicolumn{3}{|c|}{ 6- to 8-Year Lag ( $n=45,723)$} \\
\hline & Patients & $\mathrm{HR}^{*}$ & $95 \% \mathrm{Cl}$ & Patients & $\mathrm{HR}^{*}$ & $95 \% \mathrm{Cl}$ & Patients & $\mathrm{HR}^{*}$ & $95 \% \mathrm{Cl}$ \\
\hline \multicolumn{10}{|l|}{ Total alcohol, g/d } \\
\hline None & 183 & \multicolumn{2}{|c|}{1.00 (ref) } & 162 & \multicolumn{2}{|c|}{1.00 (ref) } & 135 & \multicolumn{2}{|c|}{1.00 (ref) } \\
\hline$>0$ to $<10$ & 306 & 0.81 & 0.67 to 0.98 & 272 & 0.83 & 0.68 to 1.02 & 226 & 0.84 & 0.67 to 1.05 \\
\hline$>10$ to $<15$ & 103 & 0.89 & 0.69 to 1.15 & 98 & 1.00 & 0.77 to 1.30 & 70 & 0.88 & 0.65 to 1.18 \\
\hline 15 to $<30$ & 129 & 0.98 & 0.77 to 1.24 & 109 & 0.97 & 0.75 to 1.25 & 96 & 1.06 & 0.80 to 1.39 \\
\hline$\geq 30$ & 95 & 0.93 & 0.71 to 1.21 & 85 & 0.97 & 0.73 to 1.29 & 74 & 1.04 & 0.76 to 1.41 \\
\hline \multicolumn{10}{|c|}{ Total wine, servings/wk } \\
\hline None & 318 & \multicolumn{2}{|c|}{1.00 (ref) } & 285 & \multicolumn{2}{|c|}{1.00 (ref) } & 237 & \multicolumn{2}{|c|}{1.00 (ref) } \\
\hline$>0$ to $<1$ & 160 & 0.88 & 0.72 to 1.07 & 138 & 0.91 & 0.73 to 1.12 & 110 & 0.89 & 0.70 to 1.13 \\
\hline 1 to $<3$ & 174 & 0.90 & 0.74 to 1.09 & 147 & 0.85 & 0.69 to 1.05 & 121 & 0.84 & 0.67 to 1.05 \\
\hline 3 to $<7$ & 124 & 1.15 & 0.93 to 1.43 & 122 & 1.29 & 1.03 to 1.61 & 105 & 1.36 & 1.07 to 1.73 \\
\hline$\geq 7$ & 40 & 0.98 & 0.70 to 1.37 & 34 & 0.95 & 0.66 to 1.48 & 28 & 0.93 & 0.62 to 1.39 \\
\hline \multicolumn{10}{|l|}{ Beer, servings/wk } \\
\hline None & 343 & \multicolumn{2}{|c|}{1.00 (ref) } & 319 & \multicolumn{2}{|c|}{1.00 (ref) } & 275 & \multicolumn{2}{|c|}{1.00 (ref) } \\
\hline$>0$ to $<1$ & 205 & 0.98 & 0.81 to 1.17 & 165 & 0.88 & 0.73 to 1.07 & 132 & 0.81 & 0.65 to 1.00 \\
\hline 1 to $<3$ & 102 & 0.90 & 0.71 to 1.14 & 82 & 0.82 & 0.63 to 1.05 & 61 & 0.70 & 0.52 to 0.93 \\
\hline 3 to $<7$ & 110 & 1.10 & 0.88 to 1.39 & 102 & 1.08 & 0.86 to 1.37 & 84 & 0.97 & 0.75 to 1.25 \\
\hline$\geq 7$ & 56 & 1.19 & 0.88 to 1.61 & 58 & 1.30 & 0.96 to 1.75 & 49 & 1.21 & 0.87 to 1.67 \\
\hline \multicolumn{10}{|c|}{ Liquor, servings/wk } \\
\hline None & 343 & \multicolumn{2}{|c|}{1.00 (ref) } & 316 & \multicolumn{2}{|c|}{1.00 (ref) } & 264 & \multicolumn{2}{|c|}{1.00 (ref) } \\
\hline$>0$ to $<1$ & 152 & 0.92 & 0.76 to 1.12 & 129 & 0.89 & 0.72 to 1.10 & 101 & 0.84 & 0.66 to 1.06 \\
\hline 1 to $<3$ & 81 & 0.87 & 0.68 to 1.12 & 72 & 0.88 & 0.68 to 1.15 & 66 & 0.99 & 0.75 to 1.30 \\
\hline 3 to $<7$ & 131 & 0.98 & 0.80 to 1.21 & 119 & 0.97 & 0.78 to 1.20 & 94 & 0.91 & 0.71 to 1.16 \\
\hline$\geq 7$ & 109 & 0.93 & 0.74 to 1.18 & 90 & 0.86 & 0.67 to 1.10 & 76 & 0.91 & 0.69 to 1.19 \\
\hline \multicolumn{10}{|c|}{ Red wine, servings/wk } \\
\hline None & 435 & \multicolumn{2}{|c|}{1.00 (ref) } & 391 & \multicolumn{2}{|c|}{1.00 (ref) } & 323 & \multicolumn{2}{|c|}{1.00 (ref) } \\
\hline$>0$ to $<1$ & 215 & 0.90 & 0.76 to 1.07 & 188 & 0.93 & 0.78 to 1.12 & 154 & 0.95 & 0.77 to 1.16 \\
\hline 1 to $<3$ & 102 & 1.11 & 0.88 to 1.39 & 83 & 1.07 & 0.83 to 1.37 & 74 & 1.22 & 0.94 to 1.60 \\
\hline 3 to $<7$ & 48 & 0.97 & 0.71 to 1.32 & 52 & 1.17 & 0.87 to 1.59 & 41 & 1.12 & 0.80 to 1.57 \\
\hline$\geq 7$ & 16 & 1.11 & 0.66 to 1.86 & 12 & 0.90 & 0.50 to 1.63 & 9 & 0.85 & 0.43 to 1.67 \\
\hline \multicolumn{10}{|c|}{ White wine, servings/wk } \\
\hline None & 347 & & (ref) & 309 & & (ref) & 255 & & (ref) \\
\hline$>0$ to $<1$ & 252 & 0.88 & 0.74 to 1.04 & 219 & 0.91 & 0.75 to 1.09 & 180 & 0.92 & 0.75 to 1.12 \\
\hline 1 to $<3$ & 108 & 0.91 & 0.72 to 1.15 & 94 & 0.93 & 0.73 to 1.18 & 77 & 0.92 & 0.71 to 1.21 \\
\hline 3 to $<7$ & 95 & 1.15 & 0.90 to 1.46 & 90 & 1.21 & 0.94 to 1.55 & 77 & 1.25 & 0.96 to 1.64 \\
\hline$\geq 7$ & 14 & 0.62 & 0.36 to 1.07 & 14 & 0.70 & 0.40 to 1.20 & 12 & 0.70 & 0.39 to 1.26 \\
\hline
\end{tabular}

Abbreviation: HR, hazard ratio.

*Fully adjusted models are adjusted for total energy intake (kilocalories/day, continuous); smoking status (never, past [quit $>10$ years ago], past [quit $\leq$ 10 years ago], current [ $<40$ pack-years], current [ $\geq 40$ pack-years]); body mass index ( $\mathrm{kg} / \mathrm{m}^{2}:<25,25$ to $<30, \geq 30$ ); vigorous physical activity ( $<3 \mathrm{~h} / \mathrm{wk}$, $\geq 3 \mathrm{~h} / \mathrm{wk}$ ); choline (milligrams/day, quintiles); vegetable fat (grams/day, quintiles); coffee (servings/day, quintiles); lycopene (servings/day, quintiles); whole milk (servings/day, quintiles); prostate-specific antigen screening beginning in 1994 (report of screening on the previous cycle [yes or no] and report of prostate-specific antigen screening on $\geq 50 \%$ of previous cycles [yes or no]); and diabetes (yes or no). 
TABLE A3. Alcohol Intake and Risk of Overall Mortality $(\mathrm{N}=47,568)$

\begin{tabular}{|c|c|c|c|c|c|c|}
\hline \multirow[b]{2}{*}{ Alcohol Intake } & \multirow[b]{2}{*}{ No. of Patients } & \multirow[b]{2}{*}{ Person-Years } & \multicolumn{2}{|c|}{ Age Adjusted } & \multicolumn{2}{|c|}{ Fully Adjusted ${ }^{*}$} \\
\hline & & & HR & $95 \% \mathrm{Cl}$ & HR & $95 \% \mathrm{Cl}$ \\
\hline \multicolumn{7}{|l|}{ Total alcohol, g/d } \\
\hline$>0$ to $<10$ & 1,508 & 464,674 & 0.83 & 0.80 to 0.87 & 0.85 & 0.82 to 0.89 \\
\hline$>10$ to $<15$ & 1,407 & 130,209 & 0.79 & 0.74 to 0.84 & 0.82 & 0.78 to 0.87 \\
\hline 15 to $<30$ & 1,497 & 161,910 & 0.80 & 0.76 to 0.84 & 0.81 & 0.77 to 0.86 \\
\hline Any & 6,242 & 859,562 & 0.84 & 0.81 to 0.88 & 0.85 & 0.81 to 0.88 \\
\hline \multicolumn{7}{|c|}{ Total wine, servings/wk } \\
\hline None & 1,881 & 316,642 & \multicolumn{2}{|c|}{1.00 (ref) } & \multicolumn{2}{|c|}{1.00 (ref) } \\
\hline$>0$ to $<1$ & 1,765 & 247,193 & 0.80 & 0.77 to 0.84 & 0.86 & 0.83 to 0.90 \\
\hline 1 to $<3$ & 1,289 & 270,936 & 0.74 & 0.71 to 0.77 & 0.81 & 0.78 to 0.85 \\
\hline \multicolumn{7}{|l|}{ Beer, servings/wk } \\
\hline None & 1,865 & 360,658 & \multicolumn{2}{|c|}{1.00 (ref) } & \multicolumn{2}{|c|}{1.00 (ref) } \\
\hline$>0$ to $<1$ & 1,678 & 282,290 & 0.84 & 0.81 to 0.87 & 0.87 & 0.84 to 0.91 \\
\hline 1 to $<3$ & 1,324 & 184,919 & 0.80 & 0.76 to 0.84 & 0.85 & 0.81 to 0.90 \\
\hline 3 to $<7$ & 1,065 & 147,144 & 0.85 & 0.81 to 0.90 & 0.87 & 0.82 to 0.92 \\
\hline$\geq 7$ & 1,251 & 67,942 & 1.05 & 0.98 to 1.13 & 0.89 & 0.83 to 0.96 \\
\hline Any & 5,318 & 682,295 & 0.85 & 0.82 to 0.87 & 0.91 & 0.88 to 0.95 \\
\hline \multicolumn{7}{|c|}{ Liquor, servings/wk } \\
\hline None & 1,494 & 418,275 & \multicolumn{2}{|c|}{1.00 (ref) } & \multicolumn{2}{|c|}{1.00 (ref) } \\
\hline$>0$ to $<1$ & 1,356 & 251,147 & 0.89 & 0.85 to 0.92 & 0.92 & 0.88 to 0.96 \\
\hline 1 to $<3$ & 1,336 & 154,773 & 0.74 & 0.70 to 0.78 & 0.83 & 0.78 to 0.87 \\
\hline 3 to $<7$ & 1,132 & 74,705 & 0.73 & 0.68 to 0.78 & 0.80 & 0.74 to 0.86 \\
\hline$\geq 7$ & 1,358 & 19,290 & 0.80 & 0.71 to 0.91 & 0.82 & 0.73 to 0.94 \\
\hline Any & 5,355 & 588,618 & 0.78 & 0.76 to 0.81 & 0.93 & 0.89 to 0.97 \\
\hline \multicolumn{7}{|c|}{ White wine, servings/wk } \\
\hline None & 1,869 & 352,156 & \multicolumn{2}{|c|}{1.00 (ref) } & \multicolumn{2}{|c|}{1.00 (ref) } \\
\hline$>0$ to $<1$ & 1,539 & 391,096 & 0.78 & 0.75 to 0.81 & 0.85 & 0.82 to 0.88 \\
\hline 1 to $<3$ & 1,306 & 175,856 & 0.72 & 0.68 to 0.75 & 0.81 & 0.77 to 0.85 \\
\hline 3 to $<7$ & 1,127 & 98,156 & 0.73 & 0.69 to 0.78 & 0.82 & 0.77 to 0.88 \\
\hline$\geq 7$ & 1,257 & 25,689 & 0.79 & 0.71 to 0.89 & 0.86 & 0.76 to 0.96 \\
\hline Any & 5,229 & 690,797 & 0.76 & 0.74 to 0.79 & 0.89 & 0.85 to 0.93 \\
\hline
\end{tabular}

Abbreviation: HR, hazard ratio.

*Fully adjusted models are adjusted for total energy intake (kilocalories/day, continuous); smoking status (never, past [quit $>10$ years ago], past [quit $\leq$ 10 years ago], current [ $<40$ pack-years], current [ $\geq 40$ pack-years]); body mass index ( $\mathrm{kg} / \mathrm{m}^{2}:<25,25$ to $<30, \geq 30$ ); vigorous physical activity ( $<3 \mathrm{~h} /$ wk, $\geq 3 \mathrm{~h} / \mathrm{wk}$ ); choline (milligrams/day, quintiles); vegetable fat (grams/day, quintiles); coffee (servings/day, quintiles); lycopene (servings/day, quintiles); whole milk (servings/day, quintiles); prostate-specific antigen screening beginning in 1994 (report of screening on the previous cycle [yes or no] and report of prostate-specific antigen screening on $\geq 50 \%$ of previous cycles [yes or no]); and diabetes (yes or no). Models for all-cause mortality also adjusted for parental history of myocardial infarction before 60 years of age (yes or no); comorbidities (yes or no; yes if myocardial infarction, angina, coronary artery bypass or angioplasty, stroke, emphysema or chronic obstructive pulmonary disease, or Parkinson's disease); high blood pressure (yes or no); and high cholesterol (yes or no). 
TABLE A4. Postdiagnosis Alcohol Intake and Progression to Lethal Prostate Cancer Among Men Diagnosed With Nonmetastatic Prostate Cancer in the Health Professionals Follow-Up Study $(\mathrm{N}=5,182)$

Restricted to Men Who Reported $\geq$ Two Prediagnosis

Exclude Missing Stage $(n=4,731)$

PSA Screenings $(n=2,963)$

\section{Alcohol Intake}

Total alcohol, g/d

\begin{tabular}{l}
\hline None \\
\hline$>0$ to $<10$ \\
$>10$ to $<15$ \\
15 to $<30$ \\
$\geq 30$ \\
Any
\end{tabular}

\begin{tabular}{|c|c|c|c|c|c|c|}
\hline \multirow{2}{*}{$\begin{array}{l}\text { None } \\
>0 \text { to }<1\end{array}$} & \multirow{2}{*}{$\begin{array}{r}168 \\
52\end{array}$} & \multicolumn{2}{|c|}{1.00 (ref) } & \multirow{2}{*}{$\begin{array}{l}55 \\
14\end{array}$} & \multicolumn{2}{|c|}{1.00 (ref) } \\
\hline & & 3.41 & 1.26 to 9.24 & & 9.23 & 1.04 to 82.26 \\
\hline 1 to $<3$ & 73 & 1.29 & 0.62 to 2.69 & 25 & 0.49 & 0.07 to 3.32 \\
\hline$\geq 7$ & 27 & 0.74 & 0.29 to 1.88 & 13 & 0.16 & 0.01 to 3.69 \\
\hline Any & 207 & 0.99 & 0.55 to 1.78 & 73 & 1.16 & 0.33 to 4.13 \\
\hline None & 216 & \multicolumn{2}{|c|}{1.00 (ref) } & 79 & \multicolumn{2}{|c|}{1.00 (ref) } \\
\hline$>0$ to $<1$ & 52 & 0.77 & 0.34 to 1.77 & 12 & 0.21 & 0.02 to 2.10 \\
\hline 1 to $<3$ & 52 & 1.29 & 0.60 to 2.79 & 19 & 0.38 & 0.04 to 3.29 \\
\hline 3 to $<7$ & 43 & 1.58 & 0.68 to 3.67 & 13 & 4.15 & 0.39 to 44.66 \\
\hline None & 200 & \multicolumn{2}{|c|}{1.00 (ref) } & 77 & \multicolumn{2}{|c|}{1.00 (ref) } \\
\hline$>0$ to $<1$ & 46 & 1.12 & 0.50 to 2.48 & 12 & 0.50 & 0.09 to 2.83 \\
\hline 1 to $<3$ & 30 & 1.38 & 0.49 to 3.86 & 8 & 1.41 & 0.15 to 13.42 \\
\hline 3 to $<7$ & 47 & 1.18 & 0.50 to 2.76 & 17 & 0.30 & 0.03 to 3.18 \\
\hline$\geq 7$ & 52 & 1.22 & 0.55 to 2.69 & 14 & 1.05 & 0.11 to 10.15 \\
\hline Any & 175 & 1.05 & 0.60 to 1.85 & 51 & 0.64 & 0.18 to 2.25 \\
\hline \multicolumn{7}{|c|}{ Red wine, servings/wk } \\
\hline None & 218 & \multicolumn{2}{|c|}{1.00 (ref) } & 67 & \multicolumn{2}{|c|}{1.00 (ref) } \\
\hline$>0$ to $<1$ & 62 & 0.77 & 0.38 to 1.56 & 20 & 0.49 & 0.07 to 3.21 \\
\hline$>0$ to $<1$ & 93 & 1.48 & 0.72 to 3.05 & 29 & 0.47 & 0.08 to 2.84 \\
\hline 1 to $<3$ & 34 & 1.18 & 0.47 to 2.98 & 10 & 0.56 & 0.05 to 6.57 \\
\hline 3 to $<7$ & 34 & 0.52 & 0.22 to 1.23 & 10 & 0.17 & 0.01 to 2.00 \\
\hline
\end{tabular}

Patients

$\mathrm{HR}^{*}$

$95 \% \mathrm{CI}$

$\begin{array}{lll}\text { Patients } & \mathrm{HR}^{*} & 95 \% \mathrm{Cl}\end{array}$

100

1.00 (ref)

0.58 to 2.42

$46 \quad 0.95$

$61 \quad 0.65$

0.39 to 2.31

0.29 to 1.43

0.39 to 2.87

0.51 to 1.79

0.95

38

42

16

19

13

90

0.09

0.35

1.00 (ref)

$\begin{array}{ll}0.49 & 0.10 \text { to } 2.35 \\ 0.30 & 0.03 \text { to } 2.79 \\ 0.39 & 0.07 \text { to } 2.20 \\ 0.09 & 0.00 \text { to } 1.67 \\ 0.35 & 0.09 \text { to } 1.35\end{array}$

\section{Total wine, servings/wk}

(continued on following page) 
TABLE A4. Postdiagnosis Alcohol Intake and Progression to Lethal Prostate Cancer Among Men Diagnosed With Nonmetastatic Prostate Cancer in the Health Professionals Follow-Up Study $(N=5,182)$ (continued)

Exclude Missing Stage $(n=4,731)$

\begin{tabular}{cccc} 
Alcohol Intake & Patients & $\mathbf{H R}^{*}$ & $\mathbf{9 5 \%} \mathbf{~ C l}$ \\
\hline$\geq 7$ & 8 & 0.65 & 0.14 to 2.93 \\
\hline Any & 169 & 1.14 & 0.61 to 2.14
\end{tabular}

Nonsmokers $(n=5,005)$

\section{Alcohol Intake}

Patients

Total alcohol, g/d

\begin{tabular}{l} 
None \\
\hline$>0$ to $<10$ \\
$>10$ to $<15$ \\
\hline 15 to $<30$ \\
$\geq 30$ \\
Any \\
\hline
\end{tabular}

$\begin{array}{cc}121 & 1 \\ 139 & 1.09 \\ 46 & 0.69 \\ 63 & 1.50 \\ 35 & 1.04 \\ 283 & \end{array}$

Restricted to Men Who Reported $\geq$ Two Prediagnosis PSA Screenings $(n=2,963)$

\begin{tabular}{ccc}
\hline Patients & HR $^{*}$ & $\mathbf{9 5 \%} \mathbf{~} \mathbf{~}$ \\
\hline 3 & 5.50 & 0.03 to \\
& & $1,009.49$ \\
\hline 52 & 0.66 & 0.13 to 3.43
\end{tabular}

Using Alcohol Report From First Postdiagnosis Questionnaire Only $(n=4,645)$

Total wine, servings/wk

\begin{tabular}{|c|c|c|c|c|c|c|}
\hline \multirow{2}{*}{$\frac{\text { None }}{>0 \text { to }<1}$} & \multirow{2}{*}{$\frac{193}{55}$} & \multicolumn{2}{|c|}{1.00 (ref) } & \multirow{2}{*}{$\frac{174}{48}$} & \multicolumn{2}{|c|}{1.00 (ref) } \\
\hline & & 2.94 & 1.23 to 7.03 & & 1.65 & 0.66 to 4.15 \\
\hline 1 to $<3$ & 75 & 1.38 & 0.69 to 2.77 & 78 & 0.76 & 0.38 to 1.51 \\
\hline$\geq 7$ & 28 & 0.97 & 0.40 to 2.32 & 20 & 0.57 & 0.22 to 1.52 \\
\hline Any & 211 & 1.12 & 0.65 to 1.92 & 216 & 0.90 & 0.50 to 1.60 \\
\hline None & 240 & \multicolumn{2}{|c|}{1.00 (ref) } & 200 & \multicolumn{2}{|c|}{1.00 (ref) } \\
\hline$>0$ to $<1$ & 52 & 0.60 & 0.29 to 1.26 & 52 & 0.62 & 0.28 to 1.34 \\
\hline 1 to $<3$ & 53 & 1.17 & 0.56 to 2.43 & 59 & 1.06 & 0.50 to 2.24 \\
\hline 3 to $<7$ & 46 & 1.66 & 0.75 to 3.66 & 60 & 1.16 & 0.53 to 2.53 \\
\hline$\geq 7$ & 13 & 2.65 & $\begin{array}{r}0.57 \text { to } \\
12.19\end{array}$ & 18 & 1.39 & 0.38 to 5.06 \\
\hline None & 227 & \multicolumn{2}{|c|}{1.00 (ref) } & 201 & \multicolumn{2}{|c|}{1.00 (ref) } \\
\hline$>0$ to $<1$ & 48 & 0.99 & 0.48 to 2.05 & 49 & 1.08 & 0.52 to 2.23 \\
\hline 1 to $<3$ & 29 & 1.08 & 0.40 to 2.88 & 25 & 0.73 & 0.23 to 2.29 \\
\hline 3 to $<7$ & 47 & 0.99 & 0.45 to 2.16 & 57 & 1.14 & 0.53 to 2.48 \\
\hline$\geq 7$ & 53 & 1.52 & 0.69 to 3.32 & 57 & 1.08 & 0.47 to 2.47 \\
\hline Any & 177 & 1.02 & 0.61 to 1.72 & 188 & 1.05 & 0.60 to 1.84 \\
\hline \multicolumn{7}{|c|}{ Red wine, servings/wk } \\
\hline None & 242 & \multicolumn{2}{|c|}{1.00 (ref) } & 228 & \multicolumn{2}{|c|}{1.00 (ref) } \\
\hline
\end{tabular}


TABLE A4. Postdiagnosis Alcohol Intake and Progression to Lethal Prostate Cancer Among Men Diagnosed With Nonmetastatic Prostate Cancer in the Health Professionals Follow-Up Study $(N=5,182)$ (continued)

Nonsmokers $(n=5,005)$

Using Alcohol Report From First Postdiagnosis Questionnaire Only $(n=4,645)$

\begin{tabular}{|c|c|c|c|c|c|c|}
\hline Alcohol Intake & Patients & $\mathrm{HR}^{*}$ & $95 \% \mathrm{CI}$ & Patients & $\mathrm{HR}^{*}$ & $95 \% \mathrm{CI}$ \\
\hline$\geq 7$ & 19 & 0.56 & 0.20 to 1.61 & 10 & 0.60 & 0.17 to 2.12 \\
\hline Any & 162 & 0.53 & 0.31 to 0.91 & 162 & 0.91 & 0.50 to 1.67 \\
\hline None & 232 & \multicolumn{2}{|c|}{1.00 (ref) } & 206 & \multicolumn{2}{|c|}{1.00 (ref) } \\
\hline$>0$ to $<1$ & 98 & 1.60 & 0.82 to 3.10 & 85 & 0.90 & 0.46 to 1.77 \\
\hline 3 to $<7$ & 33 & 0.53 & 0.24 to 1.15 & 46 & 1.23 & 0.54 to 2.79 \\
\hline$\geq 7$ & 7 & 0.93 & 0.21 to 4.15 & 8 & 0.40 & 0.08 to 1.98 \\
\hline Any & 172 & 1.23 & 0.70 to 2.15 & 184 & 0.76 & 0.43 to 1.36 \\
\hline
\end{tabular}

Abbreviations: HR, hazard ratio; PSA, prostate-specific antigen.

*Adjusted for energy intake (kilocalories/day); smoking status (never, past [quit $>10$ years ago], past [quit $\leq 10$ years ago], current [ $<40$ pack-years], current [ $\geq 40$ pack-years]); body mass index ( $\mathrm{kg} / \mathrm{m}^{2}:<25,25$ to $<30, \geq 30$ ); vigorous physical activity ( $<3 \mathrm{~h} / \mathrm{wk}, \geq 3 \mathrm{~h} / \mathrm{wk}$ ); coffee intake (servings/day, quintiles); diabetes (yes or no); primary treatment (radical prostatectomy, radiation, hormones, other, missing); stage at diagnosis (T1, T2, T3+, missing); Gleason grade at diagnosis ( $<7,7,>7$, missing); PSA at diagnosis (ng/dL: $<4,4$ to $<10,10$ to $<20, \geq 20$, missing); PSA screening (screening on the cycle before prostate cancer diagnosis was reported [yes or no] and intensity of screening [ $\geq 50 \%$ of previous cycles, yes or no]); and diabetes (yes or no). Beer, wine, and liquor mutually adjusted for each other. Red wine and white wine also mutually adjusted. 
TABLE A5. Postdiagnosis Alcohol Intake and Overall Mortality Among Men Diagnosed With Nonmetastatic Prostate Cancer in the Health Professionals Follow-Up Study $(N=5,182)$

Exclude Missing Stage $(n=4,731)$

\section{Alcohol Intake}

Total alcohol, g/d

\begin{tabular}{ll}
\hline None & 4 \\
\hline$>0$ to $<10$ & 1 \\
\hline$>10$ to $<15$ & 2 \\
\hline 15 to $<30$ & 1 \\
\hline$\geq 30$ & 9 \\
\hline Any
\end{tabular}

Total wine, servings/wk

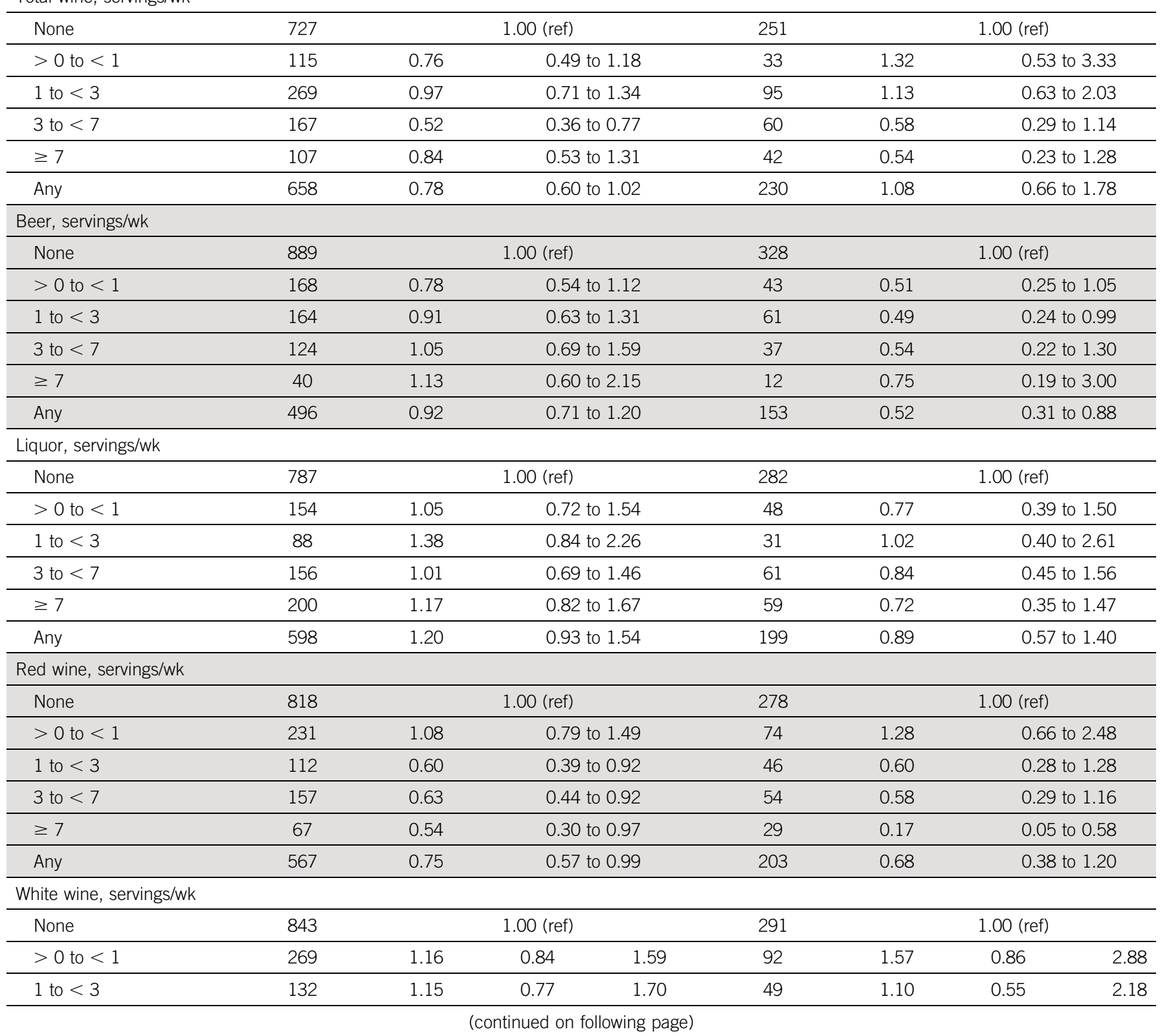
Screen $(n=2,963)$

\begin{tabular}{|c|c|c|c|c|c|}
\hline Patients & $\mathrm{HR}^{*}$ & $95 \% \mathrm{CI}$ & Patients & $\mathrm{HR}^{*}$ & $95 \% \mathrm{Cl}$ \\
\hline 433 & & (ref) & 162 & & (ref) \\
\hline 450 & 0.91 & 0.67 to 1.22 & 141 & 0.89 & 0.52 to 1.52 \\
\hline 155 & 0.82 & 0.56 to 1.21 & 57 & 0.53 & 0.27 to 1.04 \\
\hline 205 & 0.76 & 0.53 to 1.11 & 67 & 0.51 & 0.27 to 0.99 \\
\hline 142 & 0.82 & 0.54 to 1.24 & 54 & 0.43 & 0.18 to 1.02 \\
\hline 952 & 0.85 & 0.65 to 1.10 & 319 & 0.66 & 0.42 to 1.03 \\
\hline
\end{tabular}

\begin{tabular}{|c|c|c|c|c|c|}
\hline Patients & $\mathrm{HR}^{*}$ & $95 \% \mathrm{CI}$ & Patients & $\mathrm{HR}^{*}$ & $95 \% \mathrm{Cl}$ \\
\hline 433 & & (ref) & 162 & & (ref) \\
\hline 450 & 0.91 & 0.67 to 1.22 & 141 & 0.89 & 0.52 to 1.52 \\
\hline 155 & 0.82 & 0.56 to 1.21 & 57 & 0.53 & 0.27 to 1.04 \\
\hline 205 & 0.76 & 0.53 to 1.11 & 67 & 0.51 & 0.27 to 0.99 \\
\hline 142 & 0.82 & 0.54 to 1.24 & 54 & 0.43 & 0.18 to 1.02 \\
\hline 952 & 0.85 & 0.65 to 1.10 & 319 & 0.66 & 0.42 to 1.03 \\
\hline
\end{tabular}


TABLE A5. Postdiagnosis Alcohol Intake and Overall Mortality Among Men Diagnosed With Nonmetastatic Prostate Cancer in the Health Professionals Follow-Up Study $(N=5,182)$ (continued)

Exclude Missing Stage $(n=4,731)$

\begin{tabular}{ccccc}
\cline { 2 - 5 } Alcohol Intake & Patients & HR $^{*}$ & \multicolumn{2}{c}{$\mathbf{9 5 \%} \mathbf{~ C l}$} \\
\hline 3 to $<7$ & 110 & 0.70 & 0.46 & 1.06 \\
\hline$\geq 7$ & 31 & 1.03 & 0.51 & 2.1 \\
\hline Any & 542 & 1.15 & 0.86 & 1.5
\end{tabular}

Nonsmokers $(n=5,005)$

\section{Alcohol Intake}

Total alcohol, g/d

\begin{tabular}{lc} 
None & 500 \\
$>0$ to $<10$ & 491 \\
\hline$>10$ to $<15$ & 162 \\
\hline 15 to $<30$ & 213 \\
$\geq 30$ & 141 \\
Any & 1007
\end{tabular}

Total wine, servings/wk

\begin{tabular}{ll}
\hline None & 8 \\
\hline$>0$ to $<1$ & 124 \\
\hline 1 to $<3$ & 293 \\
\hline 3 to $<7$ & 17 \\
\hline$\geq 7$ & 108 \\
\hline Any & 696
\end{tabular}

811

491

162

213

141

1007

124

293

171

108

696

$\mathrm{HR}^{*}$

Beer, servings/wk

\begin{tabular}{|c|c|c|c|c|c|c|}
\hline $\begin{array}{l}\text { None } \\
>0 \text { to }<1\end{array}$ & $\begin{array}{l}978 \\
176 \\
\end{array}$ & \multicolumn{2}{|c|}{1.00 (ref) } & $\begin{array}{l}797 \\
212 \\
\end{array}$ & \multicolumn{2}{|c|}{1.00 (ref) } \\
\hline 1 to $<3$ & 188 & 1.01 & 0.71 to 1.42 & 204 & 0.93 & 0.65 to 1.32 \\
\hline$\geq 7$ & 41 & 1.28 & 0.68 to 2.42 & 72 & 1.01 & 0.58 to 1.74 \\
\hline Any & 529 & 0.93 & 0.72 to 1.20 & 647 & 0.86 & 0.67 to 1.11 \\
\hline
\end{tabular}

Liquor, servings/wk

\begin{tabular}{|c|c|c|c|c|c|c|}
\hline \multirow{2}{*}{$\begin{array}{l}\text { None } \\
>0 \text { to }<1\end{array}$} & \multirow{2}{*}{$\frac{884}{167}$} & \multicolumn{2}{|c|}{1.00 (ref) } & \multirow{2}{*}{$\frac{710}{200}$} & \multicolumn{2}{|c|}{1.00 (ref) } \\
\hline & & 1.02 & 0.71 to 1.47 & & 1.26 & 0.87 to 1.83 \\
\hline 1 to $<3$ & 92 & 1.30 & 0.80 to 2.11 & 80 & 0.77 & 0.46 to 1.30 \\
\hline$\geq 7$ & 194 & 1.05 & 0.74 to 1.49 & 242 & 1.31 & 0.92 to 1.86 \\
\hline Any & 623 & 1.12 & 0.88 to 1.44 & 734 & 1.29 & 0.98 to 1.68 \\
\hline None & 908 & \multicolumn{2}{|c|}{1.00 (ref) } & 861 & \multicolumn{2}{|c|}{1.00 (ref) } \\
\hline$>0$ to $<1$ & 247 & 1.03 & 0.76 to 1.41 & 260 & 0.85 & 0.62 to 1.18 \\
\hline 1 to $<3$ & 119 & 0.70 & 0.46 to 1.05 & 127 & 1.32 & 0.84 to 2.07 \\
\hline 3 to $<7$ & 161 & 0.65 & 0.45 to 0.93 & 139 & 0.60 & 0.40 to 0.89 \\
\hline
\end{tabular}


TABLE A5. Postdiagnosis Alcohol Intake and Overall Mortality Among Men Diagnosed With Nonmetastatic Prostate Cancer in the Health Professionals Follow-Up Study $(\mathrm{N}=5,182)$ (continued)

Using Alcohol Report From First Postdiagnosis

Nonsmokers $(n=5,005)$ Questionnaire Only $(n=4,645)$

\begin{tabular}{|c|c|c|c|c|c|c|}
\hline Alcohol Intake & Patients & $\mathrm{HR}^{*}$ & $95 \% \mathrm{CI}$ & Patients & $\mathrm{HR}^{*}$ & $95 \% \mathrm{Cl}$ \\
\hline \multicolumn{7}{|c|}{ White wine, servings/wk } \\
\hline None & 926 & \multicolumn{2}{|c|}{1.00 (ref) } & 772 & \multicolumn{2}{|c|}{1.00 (ref) } \\
\hline 1 to $<3$ & 144 & 1.28 & 0.87 to 1.87 & 162 & 1.67 & 1.14 to 2.44 \\
\hline 3 to $<7$ & 114 & 0.82 & 0.54 to 1.24 & 143 & 0.83 & 0.56 to 1.22 \\
\hline Any & 581 & 1.31 & 0.98 to 1.74 & 672 & 1.13 & 0.85 to 1.50 \\
\hline
\end{tabular}

Abbreviations: HR, hazard ratio, PSA, prostate-specific antigen; RP, radical prostatectomy.

${ }^{*}$ Adjusted for energy intake (kilocalories/day); smoking status (never, past [quit $>10$ years ago], past [quit $\leq 10$ years ago ], current [<40 pack-years], current [ $\geq 40$ pack-years]); body mass index ( $\mathrm{kg} / \mathrm{m}^{2}:<25,25$ to $<30, \geq 30$ ); vigorous physical activity ( $<3 \mathrm{~h} / \mathrm{wk}, \geq 3 \mathrm{~h} / \mathrm{wk}$ ); coffee intake (servings/day, quintiles); diabetes (yes or no); primary treatment (radical prostatectomy, radiation, hormones, other, missing); stage at diagnosis (T1, T2, T3+, missing); Gleason grade at diagnosis ( $<7,7,>7$, missing); PSA at diagnosis (ng/dL: $<4,4$ to $<10,10$ to $<20, \geq 20$, missing); PSA screening (screening on the cycle before prostate cancer diagnosis was reported [yes or no] and intensity of screening [ $\geq 50 \%$ of previous cycles, yes or no]); and diabetes (yes or no). Beer, wine, and liquor mutually adjusted for each other. Red wine and white wine also mutually adjusted. Models for all-cause mortality also adjusted for parental history of myocardial infarction before 60 years of age (yes or no); comorbidities (yes or no; yes if myocardial infarction, angina, coronary artery bypass or angioplasty, stroke, emphysema or chronic obstructive pulmonary disease, or Parkinson's disease); high blood pressure (yes or no); and high cholesterol (yes or no). 
TABLE A6. Postdiagnosis Alcohol Intake and Survival Among Patients With Prostate Cancer Diagnosed With Nonmetastatic Disease in the Health Professionals Follow-Up Study, Using Alcohol Report From 2 to 4 Years Before Current Time Period $(N=4,057)$

Lethal Prostate Cancer

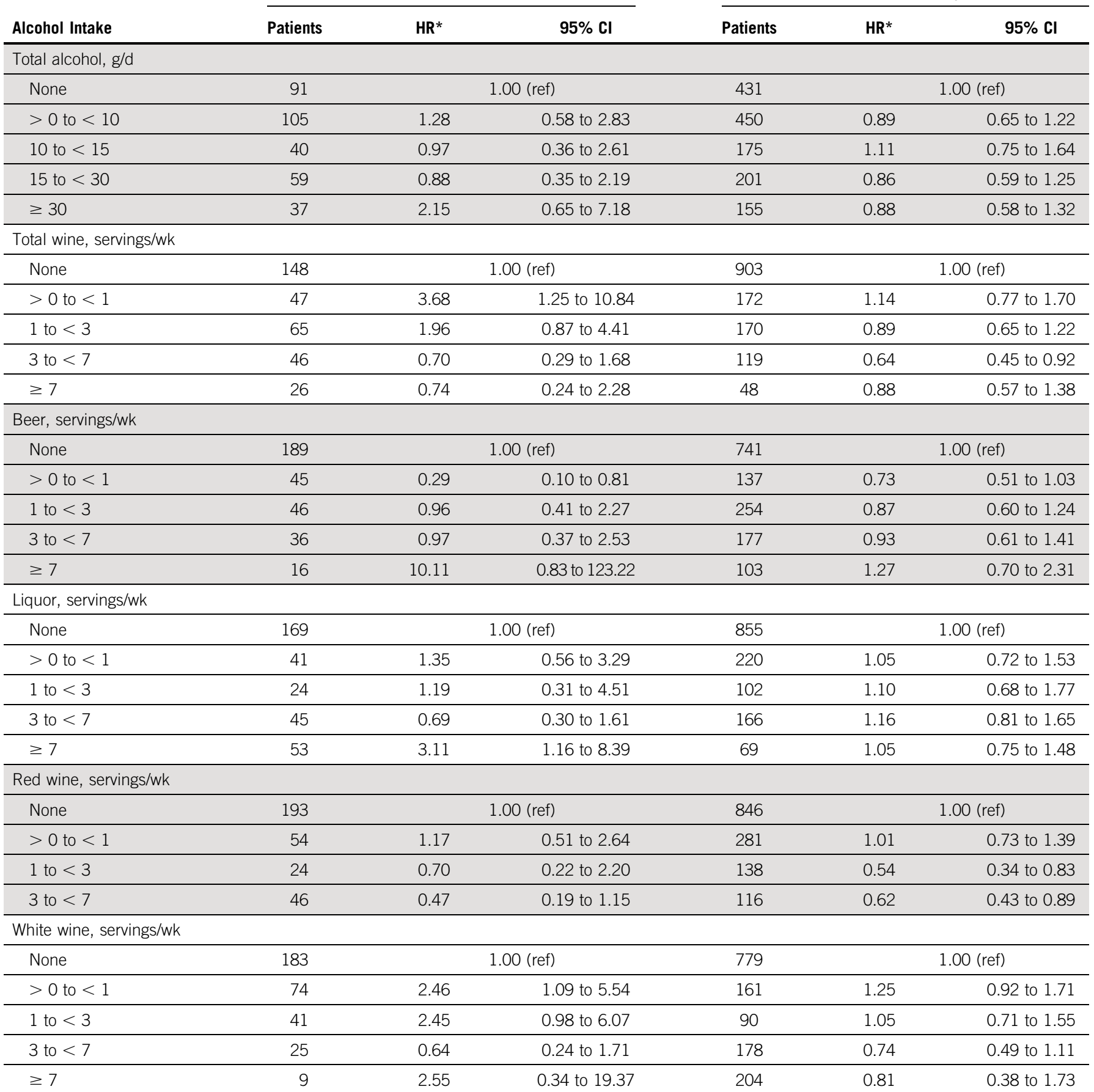

Abbreviation: HR, hazard ratio.

*Adjusted for energy intake (kilocalories/day); smoking status (never, past [quit $>10$ years ago], past [quit $\leq 10$ years ago], current [ $<40$ pack-years], current [ $\geq 40$ pack-years]); body mass index ( $\mathrm{kg} / \mathrm{m}^{2}:<25,25$ to $<30, \geq 30$ ); vigorous physical activity ( $<3 \mathrm{~h} / \mathrm{wk}, \geq 3 \mathrm{~h} / \mathrm{wk}$ ); coffee intake (servings/day, quintiles); diabetes (yes or no); primary treatment (radical prostatectomy, radiation, hormones, other, missing); stage at diagnosis (T1, T2, T3+, missing); Gleason grade at diagnosis ( $<7,7,>7$, missing); prostate-specific antigen at diagnosis (ng/dL: $<4,4$ to $<10,10$ to $<20, \geq 20$, missing); prostate-specific antigen screening (screening on the cycle before prostate cancer diagnosis was reported [yes or no] and intensity of screening [ $\geq 50 \%$ of previous cycles, yes or no]); and diabetes (yes or no). Beer, wine, and liquor mutually adjusted for each other. Red wine and white wine also mutually adjusted. Models for all-cause mortality also adjusted for parental history of myocardial infarction before 60 years of age (yes or no); comorbidities (yes or no; yes if myocardial infarction, angina, coronary artery bypass or angioplasty, stroke, emphysema or chronic obstructive pulmonary disease, or Parkinson's disease); high blood pressure (yes or no); and high cholesterol (yes or no). 
TABLE A7. Change in Alcohol Intake From Last Prediagnosis Questionnaire to First Postdiagnosis Questionnaire ( $\mathrm{N}=4,411)$

Lethal Prostate Cancer

Overall Mortality

\begin{tabular}{lccccccc} 
Alcohol Intake & Patients & $\mathbf{H R}^{*}$ & $\mathbf{9 5 \%} \mathbf{~ C l}$ & & Patients & $\mathbf{H R}^{*}$ & $\mathbf{9 5 \%} \mathbf{~ C l}$ \\
\hline Decreased & 64 & 1.33 & 0.59 to 3.00 & 192 & 1.35 & 0.93 to 1.95 \\
\hline Same & 205 & \multicolumn{2}{c}{1.00 (ref) } & 645 & \multicolumn{1}{c}{1.00 (ref) } \\
\hline Increased & 68 & 1.12 & 0.53 to 2.34 & 215 & 1.15 & 0.81 to 1.63
\end{tabular}

Abbreviation: HR, hazard ratio.

*Adjusted for energy intake (kilocalories/day); smoking status (never, past [quit $>10$ years ago], past [quit $\leq 10$ years ago], current $[<40$ pack-years], current [ $\geq 40$ pack-years]); body mass index ( $\mathrm{kg} / \mathrm{m}^{2}:<25,25$ to $<30, \geq 30$ ); vigorous physical activity ( $<3 \mathrm{~h} / \mathrm{wk}, \geq 3 \mathrm{~h} / \mathrm{wk}$ ); coffee intake (servings/day, quintiles); diabetes (yes or no); primary treatment (radical prostatectomy, radiation, hormones, other, missing); stage at diagnosis (T1, T2, T3+, missing); Gleason grade at diagnosis $(<7,7,>7$, missing); prostate-specific antigen at diagnosis (ng/dL: $<4,4$ to $<10,10$ to $<20, \geq 20$, missing); prostate-specific antigen screening (screening on the cycle before prostate cancer diagnosis was reported [yes or no] and intensity of screening [ $\geq 50 \%$ of previous cycles, yes or no]); and diabetes (yes or no). Beer, wine, and liquor mutually adjusted for each other. Red wine and white wine also mutually adjusted. Models for all-cause mortality also adjusted for parental history of myocardial infarction before 60 years of age (yes or no); comorbidities (yes or no; yes if myocardial infarction, angina, coronary artery bypass or angioplasty, stroke, emphysema or chronic obstructive pulmonary disease, or Parkinson's disease); high blood pressure (yes or no); and high cholesterol (yes or no). 